This PDF is a selection from a published volume from the National Bureau of Economic Research

Volume Title: Social Security Programs and Retirement around the World: Historical Trends in Mortality and Health, Employment, and Disability Insurance Participation and Reforms

Volume Author/Editor: David A. Wise, editor

Volume Publisher: University of Chicago Press

Volume ISBN: 0-226-90309-5; 978-0-226-90309-5

Volume URL: http://www.nber.org/books/wise11-1

Conference Date:

Publication Date: September 2012

Chapter Title: The Long-Run Growth of Disability Insurance in the United States

Chapter Author(s): Kevin Milligan

Chapter URL: http://www.nber.org/chapters/c12391

Chapter pages in book: (p. 359 - 389) 


\section{The Long-Run Growth of Disability Insurance in the United States}

Kevin Milligan

\subsection{Introduction}

The Social Security Disability Insurance program provided benefits for over 8 million Americans in 2010. The pace of growth of public expenditures in this program, however, is pushing hard against fiscal constraints. Autor and Duggan (2006) project a "crisis" if no serious reforms are attempted. It is in this context that the sources of growth of Social Security Disability Insurance are being examined.

In this chapter, I pursue two goals. First, I provide long time series of data from a variety of sources related to Social Security Disability Insurance. These long time series, with data stretching almost sixty years from 1950 to 2009 , allow for perspective and context on the different potential causes of the growth of the program. The second goal is to provide data that are comparable to what is available in other countries in this project. This comparability will help place the experience in the United States in context, and the cross-country comparisons may also yield important insights.

There are three major findings of the chapter. First, health (as measured by mortality and self-assessed health) seems to have little relationship to any observed trend in the Social Security Disability Insurance program. Second, legislative and administrative changes such as benefit formulas, screening rules, and eligibility criteria have a very clear and large impact on recipiency. Finally, labor market trends, such as the emergence of cohorts of women

Kevin Milligan is associate professor of economics at the University of British Columbia and a research associate of the National Bureau of Economic Research.

I thank the organizers of the NBER International Social Security Project and other country teams for their suggestions. For acknowledgments, sources of research support, and disclosure of the author's material financial relationships, if any, please see http://www.nber.org/chapters /c12391.ack. 
with long attachment to the labor force, can also make a large difference to long-run trends in Disability Insurance recipiency.

The chapter is laid out as follows. First, I review the details of the current working of the Social Security Disability Insurance program and how the program has developed through time. Next is a brief review of the relevant research. I then turn to a description of the data sources used here, followed by a thorough discussion of the time series and cross-sectional graphs that make up the analysis of this chapter. I conclude with a summary of the findings.

\subsection{The Development of Social Security Disability Insurance}

I begin with a description of the current state of the Social Security Disability Insurance (hereafter SSDI) program, including eligibility and benefit calculation rules. I also briefly describe related programs. Following this exposition of the current rules, I go through the history of the program, pointing out major changes that may have an impact on the behavior of the beneficiaries of the program.

\subsubsection{Current Benefit Rules for SSDI and Related Programs}

Benefits under SSDI are earnings-related. Qualification depends on a system of "credits." Credits depend on meeting a minimum level of earnings, and up to four credits are available each year. Generally, an applicant needs to have earned twenty credits over the last ten years, and up to forty overall. ${ }^{1}$ The latter qualification rule depends on age, though, so those under age sixty-two can qualify with fewer than forty overall credits. ${ }^{2}$ The disability must be found to be "severe" and expected to last at least twelve months (or be expected to result in death).

The benefit formula uses many of the same features as for Social Security Old Age benefits. Monthly earnings over the lifetime are updated to current dollar levels using an inflator that depends on the average earnings growth in the economy. ${ }^{3}$ Some periods of low earnings may be discarded, and covered earnings are capped at a maximum level. ${ }^{4}$ The result of this calculation is the Average Indexed Monthly Earnings, or AIME. The AIME is then put through a nonlinear benefit schedule that replaces 90 percent of AIME up to a first "bend point," 32 percent up to a second bend point, and 15 percent of AIME after that. The bend points in 2010 are $\$ 761$ and $\$ 4,516$ per

1. For 2010, a credit is earned for each $\$ 1,120$ of wages in a year, up to four credits per year. This amount is indexed to average wages.

2 . There is a sliding scale. Those under age forty-two need only twenty overall credits, and this amount increases by age until it reaches forty required credits at age sixty-two. Under age thirty-one, there are also lower qualifying conditions for work over the last ten years.

3. Specifically, earnings at time $t$ are inflated to time $T$ using the ratio of economywide average earnings at times $T-2$ and $t$.

4. The Social Security cap for 2010 is $\$ 106,800$. 
month. Benefits are partially taxable, depending on other sources of income. Overall, only one-third of all Social Security recipients pay any tax on their benefits. The average monthly benefit as of August 2010 was $\$ 1,066$. When the recipient reaches the Federal Retirement Age, the benefit is transformed into a Social Security Old Age benefit. ${ }^{5}$

Social Security Disability Insurance is funded as part of the Federal Insurance Contributions Act (FICA) package of payroll taxes on employers and employees. ${ }^{6}$ There is an explicit amount, currently 0.9 percent on employers and employees, set aside for SSDI. Payment for SSDI is made for earnings up to the annual cap, currently at $\$ 106,800$. The self-employed must pay both employer and employee portions, totaling 1.8 percent. The inflows and outflows on the overall Social Security and the SSDI accounts are kept separately but are also included on the unified federal government budget. There have been periodic changes to the FICA rates, most recently in 1990 .

Beyond SSDI, there are other recourses for those unable to work. First, workplace injuries are insured by state-level workers' compensation systems. These systems vary dramatically by state, incorporating different mixes of private and public provision, employer mandates, and regulation. Second, those who are disabled (or blind) and have quite low incomes can be eligible for Supplementary Security Income. This program has strict asset and income tests, and the benefit levels are quite modest ( $\$ 674$ per month for singles and $\$ 1,011$ per month for couples in 2010). There are nearly the same number of beneficiaries of Supplementary Security Income as SSDI (although Supplemental Security Income also covers lower-income people over sixty-five), but the average benefit of $\$ 498$ is around half that for SSDI. These benefits may be combined with SSDI benefits, providing income and asset tests are met. Finally, state-run unemployment insurance and welfare programs may also pick up those not qualifying for other programs. In particular, Autor and Duggan (2003) find substantial substitution between unemployment insurance and SSDI among older, lower-educated workers.

\subsubsection{Historical Development of SSDI}

The Social Security Disability program was added to the existing Social Security old age retirement benefits in $1956 .{ }^{7}$ The idea of disability insurance had been an active area of discussion throughout the 1940s and 1950s, but concerns over the definition of disability, how to administer the program,

5. The Federal Retirement Age is being moved from age sixty-five to age sixty-seven across cohorts. It was sixty-five for those hitting age sixty-five before 2003 and reached sixty-six for those hitting sixty-six in 2009. By 2027, it will be at age sixty-seven.

6. FICA stands for Federal Insurance Contributions Act. Also included in the package are amounts for Social Security retirement and survivors benefits and Medicare.

7. This discussion draws on Autor and Duggan (2006), Berkowitz (1989, 2000), and Social Security Administration (1986, 2009). 


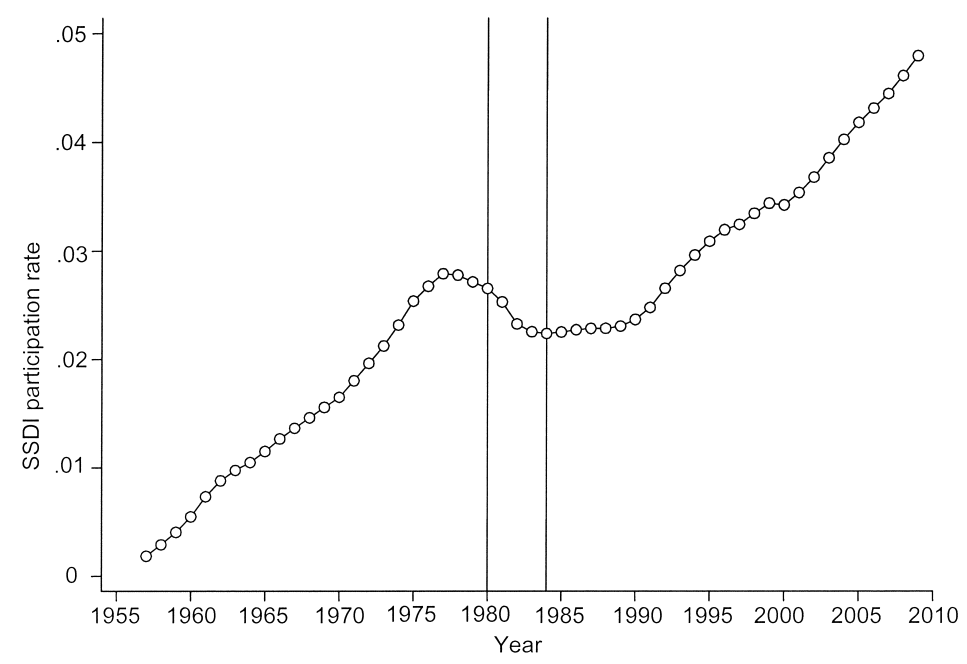

Fig. 10.1 Social Security Disability Insurance recipiency, men and women

Sources: Social Security Administration and Census data.

Note: Total number of SSDI recipients who were workers (i.e., not dependents or spouses) divided by population age twenty-five to sixty-four.

and how to structure the benefits slowed its introduction. In the following, I first describe the evolution of eligibility rules, then discuss how the benefit formula has changed. The overall trends in uptake are shown in figure 10.1, which graphs the number of Social Security Disability Insurance recipients who were workers, divided by the population age twenty-five to sixty-four, both sexes combined. ${ }^{8}$

As part of the compromise to get the bill passed in 1956, SSDI was limited to those aged fifty to sixty-four with an "inability to engage in substantial gainful activity because of any medically determinable permanent physical or mental impairment." The disability had to be experienced for a continuous period of six months. Eligibility was expanded to those under age fifty in 1960, and, in 1965, the requirement for permanent disability was relaxedone only had to have a disability expected to last a year or more. Specifically, the legislation now stated that the disability "be expected to last for a continuous period of not less than 12 months." This led to some increase in uptake of SSDI, and a 1967 amendment reemphasized the medical nature of disability and changed the definition to a "disability that precludes engagement in any substantial gainful work existing in the national economy." In 1972 , the continuous months of disability requirement was relaxed from six to five months.

8. Only a small fraction of SSDI recipients are under age twenty-five. The magnitudes on this graph match those in Autor and Duggan (2006) quite closely. 
Large increases in the SSDI rolls through the 1970s led to concerns about the fiscal cost of the program. Starting in 1977, there was a move toward tightening the medical screening done by the state-level boards in charge of the initial screening for SSDI. Gruber and Kubik (1997) estimate that denial rates increased from 53.8 percent to 69.3 percent over the 1977 to 1980 period. This pressure on the program continued with legislation in 1980 that made it harder to get benefits, changed the structure of benefits, and imposed more frequent medical reviews on those who were already receiving benefits.

These measures were effective in reversing the upward trend in SSDI receipt. However, they spawned a political backlash resulting in the Social Security Disability Benefits Reform Act of 1984. This legislation had a major impact on the program. The eligibility criteria shifted from medical to functional, as the test for disability became the "ability to function in a work-like setting." Assessments were also changed substantially, with pain and discomfort given greater weight, allowing for multiple minor impairments to "add up" to a disability and relaxed assessment of mental health and musculoskeletal damage. There was also a shift in the emphasis away from the Social Security medical assessment toward the person's own health care provider. In sum, these reforms made the system more complex, more liberal in eligibility, and more subjective.

On the benefit side, SSDI eligibility brought eligibility to Medicare coverage as well, starting in 1973. The last major legislative change was in 1978. In that year, the current system of calculating the AIME and putting it through the "bend point" formula was established. The replacement rates used previously were modified in this reform, and also the indexing of the "bend points" to average wages was regularized. The impact of this change has been greater than was likely anticipated because of the growth in earnings inequality over the last thirty years. Higher earnings for those at the top pulled up average earnings more quickly than the growth of earnings at lower levels of the earnings distribution. Autor and Duggan (2003) calculate that between 1979 and 1995, average real earnings for those without a high school degree fell by 19.5 percent, but the average wage calculated by the Social Security Administration went up by 21.6 percent. This effectively raised replacement rates because earnings were updated using the high average wage index, and the bend points moved up quickly, which allowed more of the AIME to fall in the 90 percent replacement rate range. For those at the 10th percentile of earnings, Autor and Duggan (2003) estimate that this difference in earnings growth had the impact of raising replacement rates from 52 percent to 74 percent.

A number of papers have addressed the growth in SSDI. Most recently, Duggan and Imberman (2009) set out five potential reasons for the growth. First are the 1984 screening and eligibility changes. Second, replacement rates have increased substantially for those at lower earnings levels, as described in the preceding. Third, as more females joined the workforce, they 
became newly eligible for SSDI. Fourth, the overall population is aging. Fifth and finally, economic conditions may have provided incentives to shift into SSDI. In their simulations, Duggan and Imberman (2009) find that the eligibility changes, economic conditions, and increased replacement rates are most important for men. For women, economic conditions are not as important, but increased disability insurance (DI) coverage because of higher employment levels is important.

\subsection{Other Research}

There is an extremely large and extensive literature on the impact of SSDI on labor market decisions. Instead of an extensive review of the literature, I aim here to point out the major findings of the literature.

Research in the 1970s and 1980s tended to find large disincentive effects. For example, Parsons (1980) can attribute the entire decline in the employment of older male workers to increasing DI uptake. Bound (1989), however, finds smaller difference in the work behavior of those who applied and received DI and those who applied and were rejected. His findings suggest that DI can explain less than half of the nonparticipation of older males. Gruber and Kubik (1997) find that the state-varying tightening of medical screening in the late 1970s did have a substantial effect on DI uptake, especially on those who were seemingly less disabled. Autor and Duggan (2003) exploit cross-state differences in the industrial composition of wages to investigate how benefit replacement rates influence DI applications and uptake. They find, for lower-educated men and women, that higher replacement rates can lead negative labor demand shocks to translate into larger DI case loads. Moreover, some of this comes out of what would have been observed previously as unemployment, suggesting some substitution across benefit programs for those not currently working. Autor and Duggan (2006) provide a recent survey of the literature, with projections suggesting that, without reforms, the program will continue to grow in size.

\subsection{Data Sources}

One of the goals of this chapter is to provide the longest-possible time series of data across measures of employment, SSDI usage, and health. This goal means some compromises between the detail available and the length of the time period that may be analyzed when choosing the appropriate data sets.

There are three primary data sets used in this analysis. For both the labor market and program participation data, I employ the March Current Population Survey (CPS). This survey extends back to 1962 and has detailed information on employment and income sources. The level of detail of the data improves through time with the CPS. There are also some questions on 
self-assessed health that I use. The mortality data comes from the Human Mortality Database, which combines data from the US Census and the National Center for Health Statistics. ${ }^{9}$ Finally, the General Social Survey has subjective health questions on self-assessed health and activity limitations that are useful for the analysis. I use the combined 1972 to 2008 database prepared by the National Opinion Research Center. ${ }^{10}$ For both the CPS and the General Social Survey, I use the provided survey weights to account for survey design and sampling. To these surveys, I add data taken from administrative publications of the Social Security Administration.

\subsection{Results}

The analysis examines the long-run trends in health, employment, and program participation. I do so by creating time series graphs of older Americans, separately by sex. The first set of results looks at mortality and at health. The second group of results studies program participation. Third, I search for links between labor market behavior and disability. Finally, the relationship between health and disability is explored.

\subsubsection{Mortality and Health}

Mortality is the first focus of the analysis. Mortality has the advantage of being an objective measure of health. It is available for long time periods, is comparable across countries, and comes from population data rather than a survey. Mortality is, however, a coarse measure of health. After graphically characterizing the trends in mortality in several ways, I compare the trends in mortality to those seen in more subjective and subtle measures of health.

The mortality rate at a given age is determined by dividing the number of deaths by the population at that age. I do this separately by sex for each year available in the data. I use data spanning the fifty-six years from 1950 to 2006 in order to examine the long-run trends.

The first analysis of mortality takes the mortality rate of sixty- and sixtyfive-year-olds in 1950. For subsequent years, I denote the age at which the 1950 level of mortality is reached. That is, how much older do you have to be to have the same level of mortality as someone in 1950? These data are graphed in figure 10.2 separately for males and females.

In 1950, men aged sixty had a mortality rate of 2.52 percent. By 1970, it took to age 61.03 to hit this same 2.52 percent level of mortality - an extra year of life. ${ }^{11}$ Over the next twenty-year period, however, the age at which 1950 levels of age sixty mortality are seen is not until age 65.31 . By the last

9. See http://www.mortality.org.

10. See http://www.norc.uchicago.edu/GSS+Website/.

11. I use linear interpolation to determine the age at which age sixty mortality is reached. For example, the target age sixty mortality of 2.52 percent is 3 percent of the way between ages sixty-one and sixty-two, so I calculate that the age-sixty equivalent age is 61.03 . 


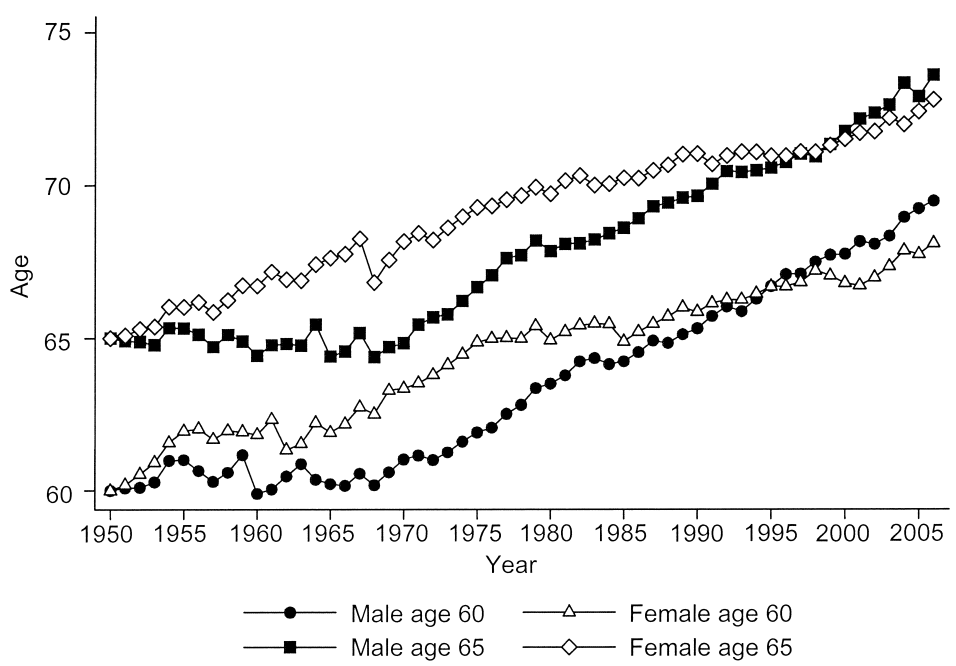

Fig. 10.2 Age at which aged sixty and sixty-five 1950 mortality level is reached Sources: Mortality data from National Center for Health Statistics and US Census.

year in the data, 2006, this had risen to 69.48. This is a substantial change in mortality over this half-century time period.

Figure 10.2 also shows the results for aged sixty women. In 1950, the mortality rate for women aged sixty was 1.48 percent. The female mortality rate dropped more quickly in the 1950s and 1960s than it did for men, meaning that by 1970 the age sixty level of mortality was not reached until age 63.35, which is an improvement more than two years greater than what was seen for men. However, the men close the gap through the 1970s and 1980s. By the 1990s, the gains in female mortality seem to level out, reaching an age of 68.1 by 2006 .

At age sixty-five, the pattern is very similar. The beginning mortality rate for men is 3.62 percent and for women is 2.22 percent. Men's mortality is actually worse in 1970 than in 1950, with those at age 64.84 having the equivalent mortality as an age sixty-five man in 1950. However, after 1970 substantial and consistent gains for men take the age at which age sixty-five mortality is reached to 73.60 by 2006 . This is a gain of 8.6 years, or 13.23 percent over age sixty-five. For age sixty male mortality, the gain was only slightly more at 15.84 percent. For women, there were gains in the 1950s and 1960s, but not over the next twenty-year period. By 2006, the age at which age sixty-five 1950 mortality was reached was 72.80 .

Figure 10.3 explores how cross-sectional mortality has changed from 1950 to 2006, for both males and females. This helps to understand if the gains in mortality were across all ages or concentrated at certain age ranges. 


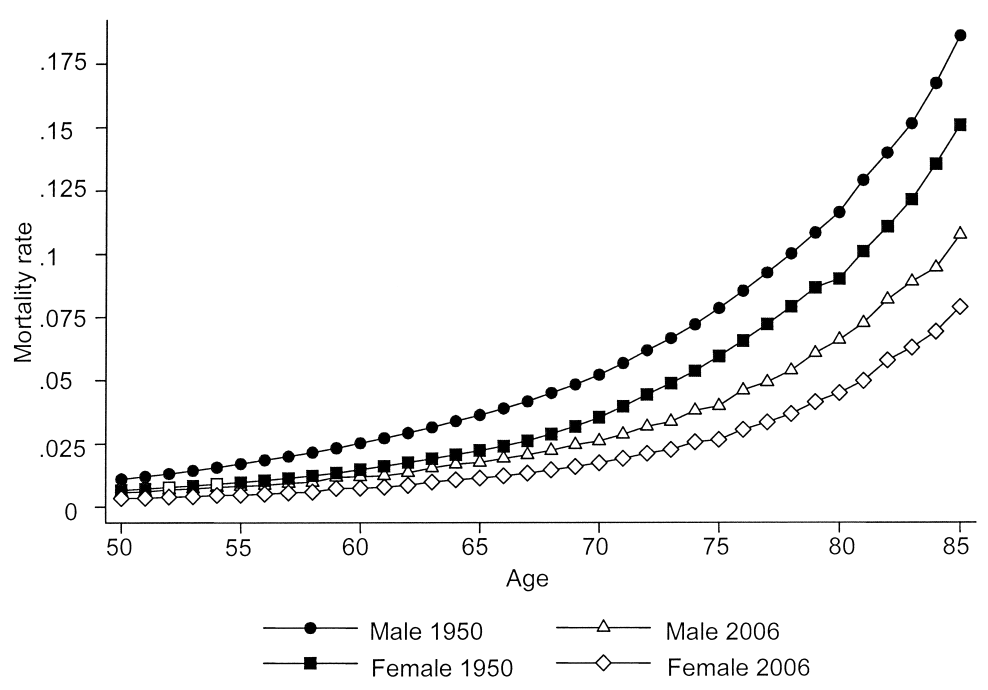

Fig. 10.3 Cross-sectional mortality in 1950 and 2006

Sources: Mortality data from National Center for Health Statistics and US Census.

Male mortality seems to drop fairly consistently across all age ranges. At age eighty, the drop is from 11.6 percent to 6.6 percent, or a 43.2 percent drop. At age sixty, it is a drop from 2.52 percent to 1.20 percent, or a 53.5 percent drop. Women also saw consistent gains across all ages, with an improvement of 50 percent at age eighty; from a 9.00 to a 4.50 percent mortality rate. Other ages saw similar improvements.

Figures 10.4 and 10.5 show the age-specific mortality across time for ages fifty-five, sixty, and sixty-five. These graphs confirm what was seen earlier in figure 10.2. Mortality rates of men in figure 10.4 stay roughly constant until 1970, when serious improvements start at all ages. For women in figure 10.5, the improvements are sharpest in the first twenty years of the data.

To see how well these mortality trends reflect more subtle measures of health, I now add some self-assessed measures of health to the analysis. From the General Social Survey, I take the proportion of respondents who answer "fair" or "poor" to the question on self-assessed health. ${ }^{12}$ This is available for the years 1972 to 2008. From the Current Population Survey, I use a similar self-assessed heath question, available only from 1995 onward. ${ }^{13}$ Finally, I form an indicator for respondents having a limit on the amount of work they can do because of a disability. This variable is also from

12. The question is the GSS is "Would you say your own health, in general, is excellent, good, fair, or poor?"

13. The question in the CPS is "Would you say ...'s health in general is." Valid responses are excellent, very good, good, fair, and poor. 


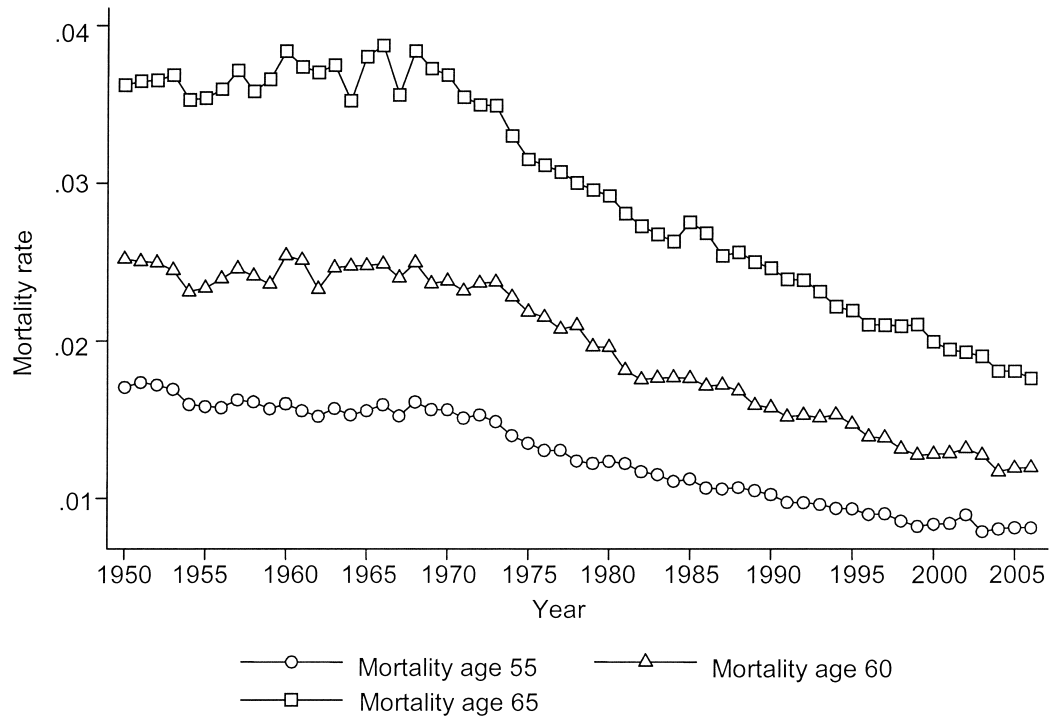

Fig. 10.4 Mortality at specific ages for men

Sources: Mortality data from National Center for Health Statistics and US Census.

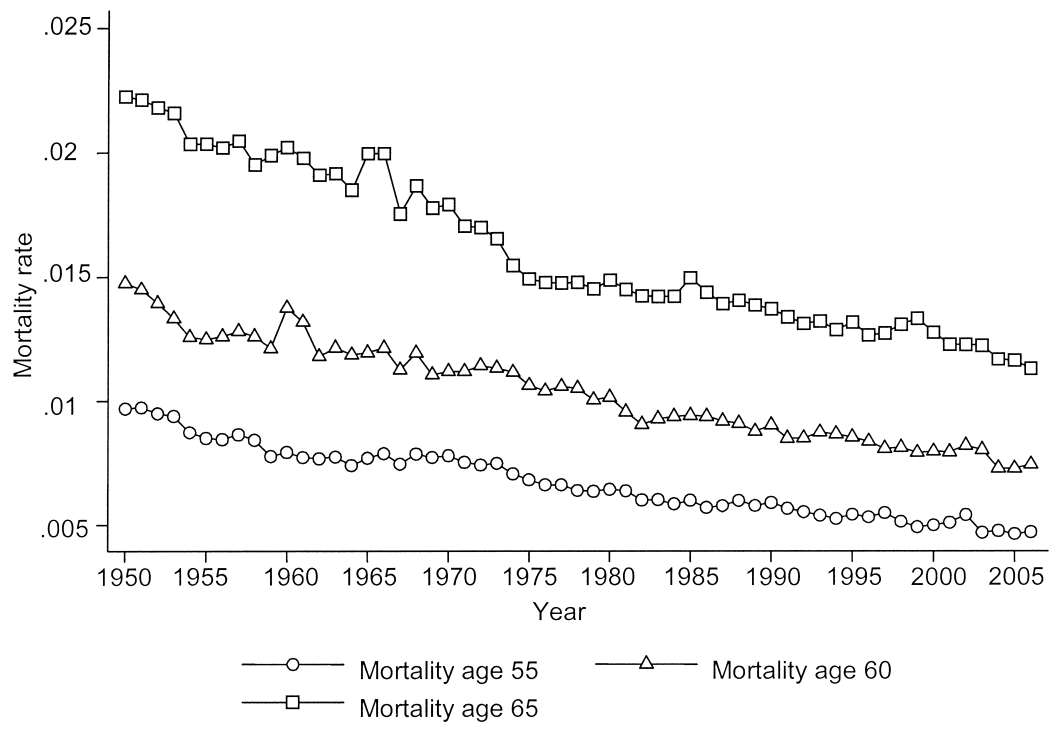

Fig. 10.5 Mortality at specific ages for women

Sources: Mortality data from National Center for Health Statistics and US Census. 


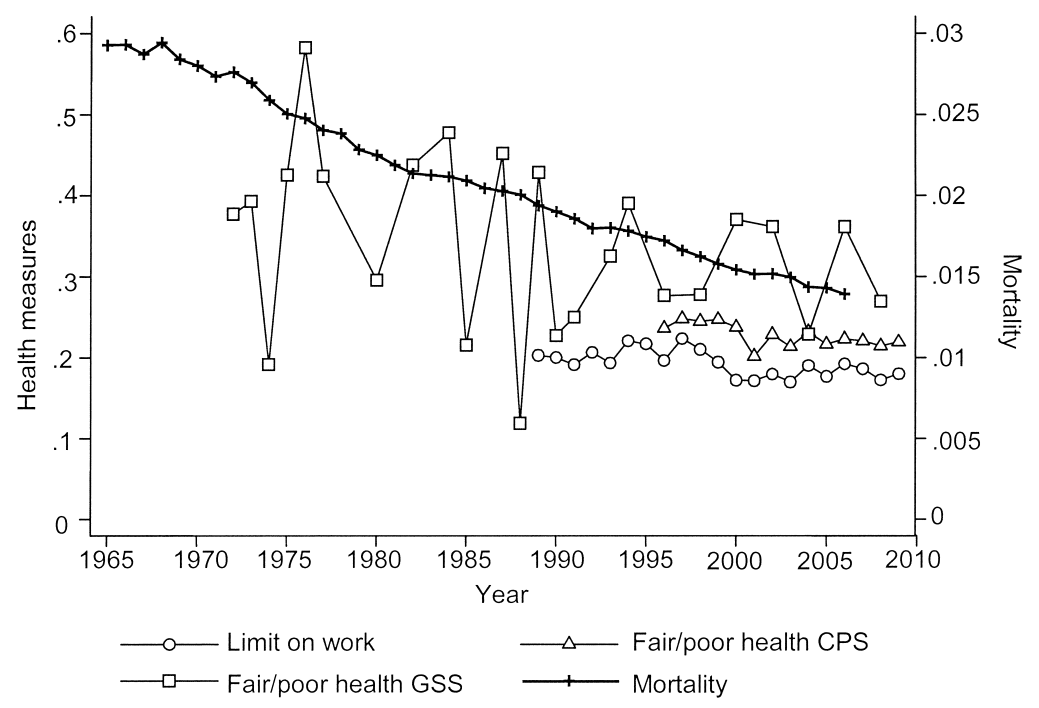

Fig. 10.6 Health and mortality for men aged sixty to sixty-four

Sources: Mortality data from National Center for Health Statistics and US Census. Health data from General Social Survey and Current Population Survey.

the CPS and seems to be broader in definition than what is used by SSDI for determining eligibility. ${ }^{14}$ It is available from 1989 onward.

Figure 10.6 graphs these three subjective health measures on the left axis and mortality on the right axis for men aged sixty to sixty-four. Mortality declines almost by half over the time period 1965 to 2006. The General Social Survey (GSS) measure of self-assessed health is quite noisy from year to year, most likely because of sampling variation related to the smaller sample size. There does appear to be a downward trend in this variable through time, however, with the 1970s, on average, showing worse health. The two CPS measures do not display any noticeable trend, but they are available only for shorter time windows.

For women, the same data are graphed in figure 10.7. Over this time period, the improvement in mortality for women is not as large, as the period of greatest mortality improvement for women was 1950 to 1970, which is mostly before the time window covered in this graph. There is a more clear decline in the GSS measure of fair or poor health than there was for men. In the 1970s, this measure showed levels around 0.5, but, by the 1990s, this had declined to around 0.3 . The CPS measure of fair or poor health shows

14. The question in the CPS is "Does ... have a health problem or a disability which prevents work or which limits the kind or amount of work." 


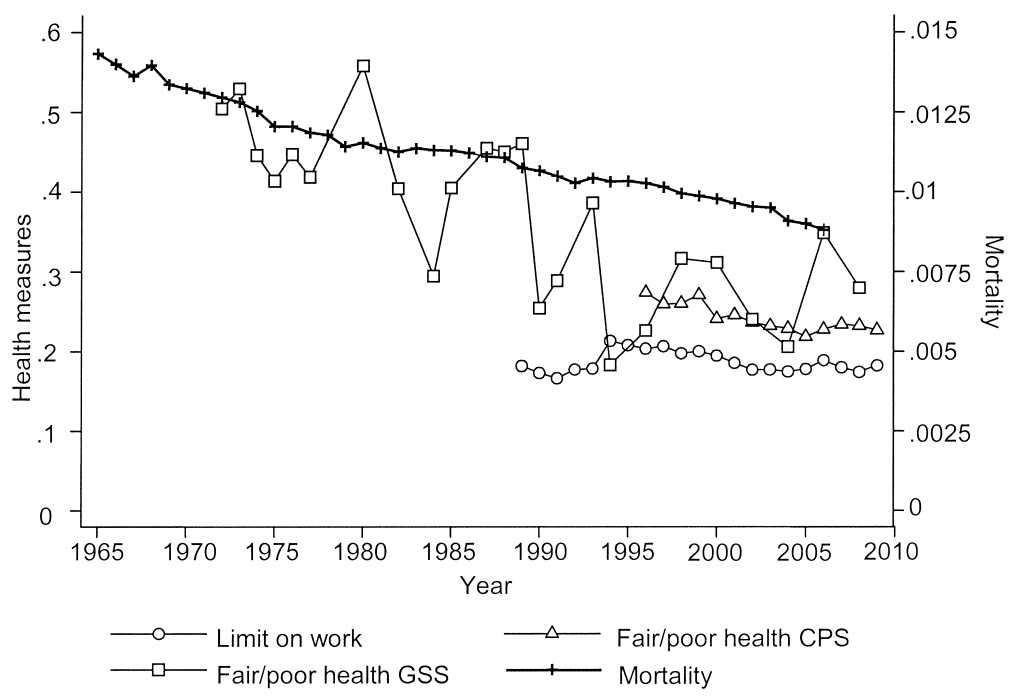

Fig. 10.7 Health and mortality for women aged sixty to sixty-four

Sources: Mortality data from National Center for Health Statistics and US Census Bureau. Health data from General Social Survey and Current Population Survey.

declines over the time period it is available, while the measure of health limitations goes up until 1994 before declining.

Another way to look at the relationship between self-assessed health and mortality is to look at how the age patterns have changed through time. In figure 10.8, I show mortality and the proportion with fair or poor health for men in the 1970s and the 2000s. The health data here come from the National Health Interview Survey. At age sixty in the 1970s, mortality is 0.022 and the incidence of fair or poor health is 0.215 . By the 2000s, however, it took until age sixty-seven to reach that same level of mortality and until age sixty-eight to reach that level of fair or poor health. In this way, it seems clear that there have been similar improvements in both measures of health through time.

For females in figure 10.9, the gain in mortality through time isn't as strong as it is for the incidence of fair or poor health. However, both show strong improvements over this thirty-year period.

In summary, the data clearly show large improvements in mortality rates both for men and women since 1950. A correspondence of mortality with subjective measures of health is present, as both are seen to be improving through time.

\subsubsection{Programs and Participation}

I now turn to analysis of program participation using data from two sources. The primary source is the CPS, which started to report the receipt of different types of benefit income starting in 1970. Five variables are formed 


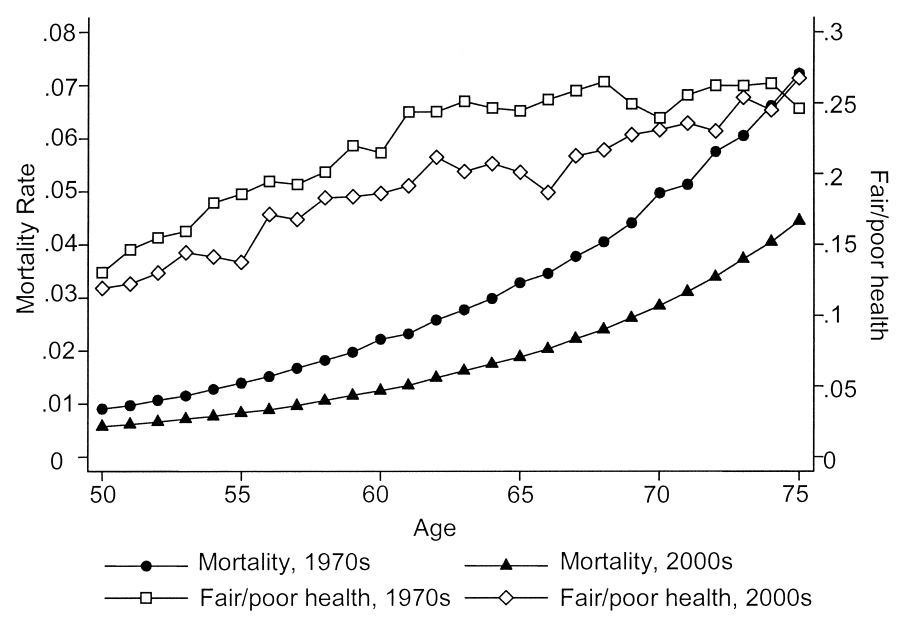

Fig. 10.8 Health and mortality for men by age, 1970s and 2000s

Sources: Mortality data from National Center for Health Statistics and US Census Bureau. Health data from National Health Interview Survey.

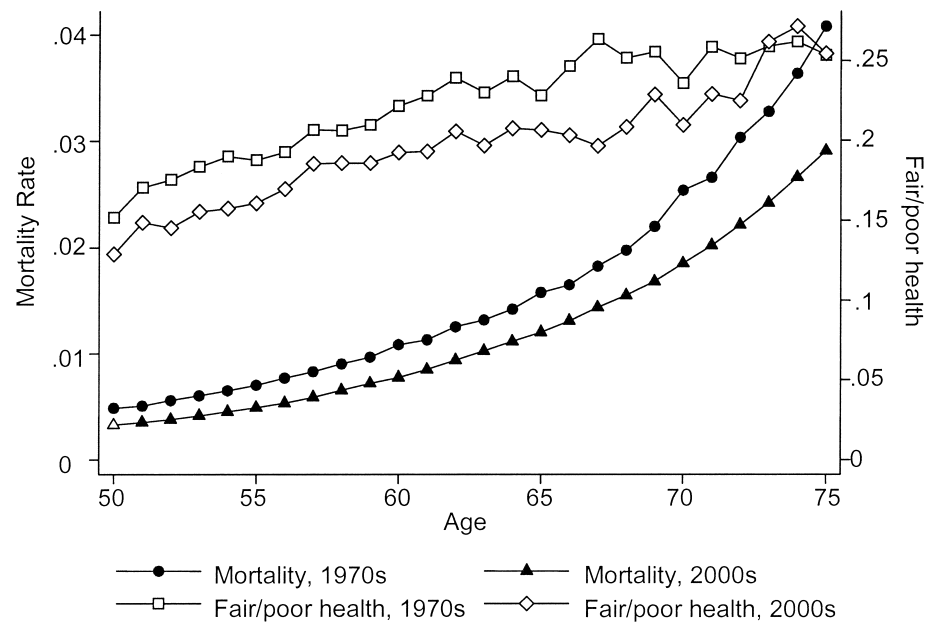

Fig. 10.9 Health and mortality for women by age, 1970s and 2000s

Sources: Mortality data from National Center for Health Statistics and US Census Bureau. Health data from National Health Interview Survey.

from this source, including dummies indicating receipt of Social Security, Unemployment Insurance, public assistance or welfare, veterans' benefits, and workers' compensation. For the Social Security dummy, the data do not distinguish the type of benefit (i.e., Old Age, Survivor, Disability, etc.). The second source used here is the administrative data from the Social Security Administration (SSA) containing counts of all SSDI beneficiaries by age 
group and year. For this, I use receipt of the Disabled Workers category of benefit, rather than children and widow benefits. These counts are normalized by corresponding age-sex-year population estimates from the United States Census Bureau.

Figure 10.10 shows the receipt of these six measures of public benefits by age group for males in 1970. Until age sixty, Veterans' Benefits constitute the largest proportion take-up of any of the benefits. Unemployment Insurance take-up is fairly constant across age groups until age sixty-five at around 4 percent. Social Security benefits (from the CPS) and SSDI take-up (from the SSA) are very close to each other and rising across age groups. At age sixty to sixty-four, Social Security participation jumps higher as benefits can be taken at the Early Retirement Age of sixty-two.

The women are graphed in figure 10.11. There are several striking differences. First, Veterans' Benefits play a much smaller role for women, owing to the sex difference in rates of military service. Social Security benefit receipt (from the CPS) is distinctly higher than SSDI receipt, reflecting the fact that many women receive survivor benefits. The level of SSDI receipt is much lower, and the slope less steep, than for men. This in part is driven by the lower labor force participation of women in 1970 - many do not qualify for SSDI because of the work requirements. For similar reasons, the proportion of women on Unemployment Insurance is noticeably lower than for men in figure 10.10 .

The next two figures turn the clock forward to 2009 and repeat the same analysis. Figure 10.12 shows the men. Veterans' Benefits now play a much

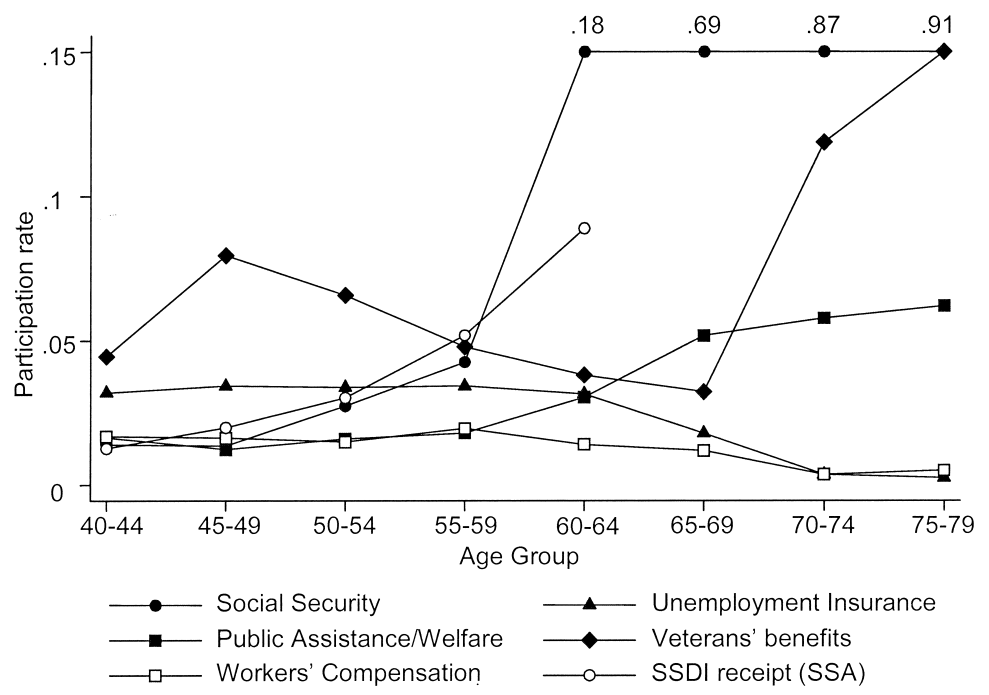

Fig. 10.10 Program participation for men, 1970

Sources: Current Population Survey and Social Security Administration. 


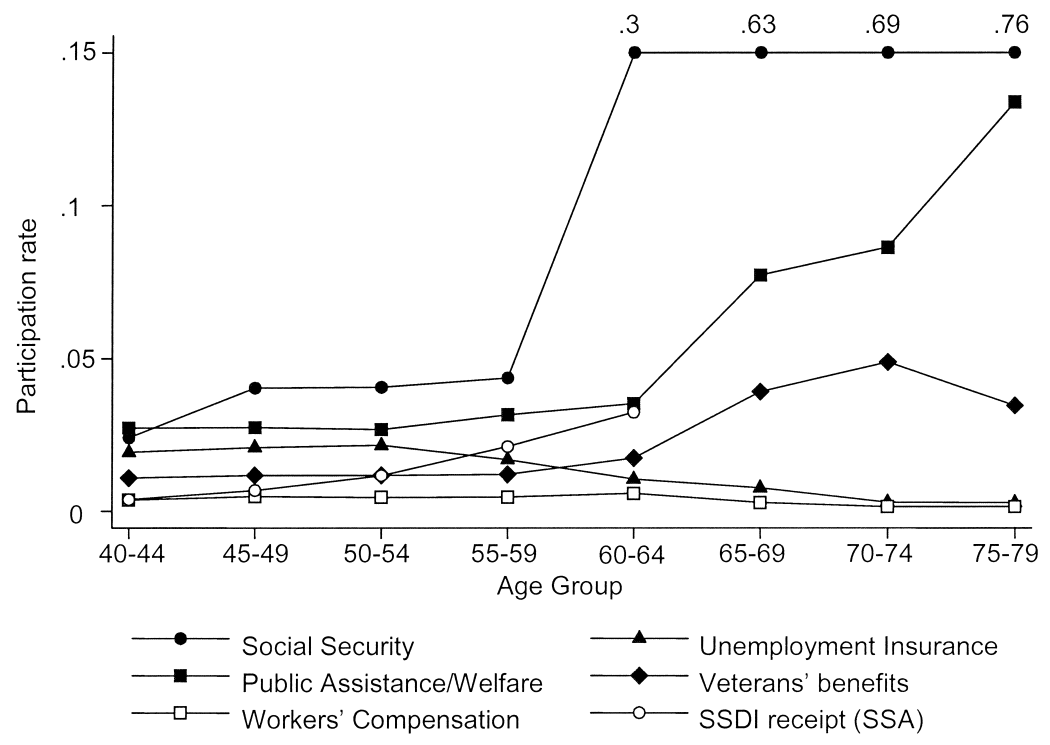

Fig. 10.11 Program participation for women, 1970

Sources: Current Population Survey and Social Security Administration.

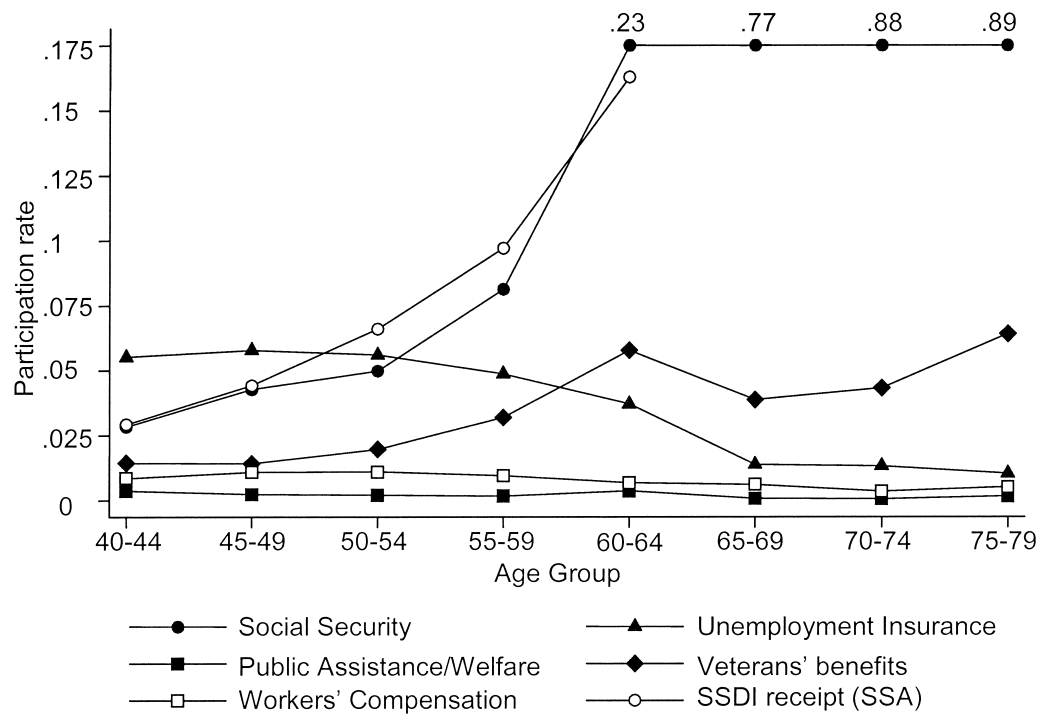

Fig. 10.12 Program participation for men, 2009

Sources: Current Population Survey and Social Security Administration. 


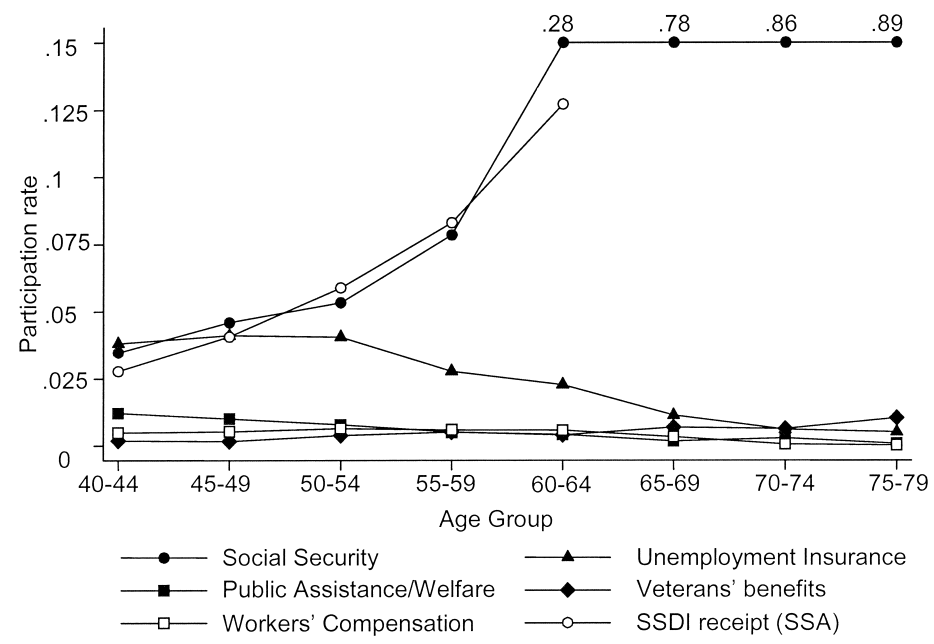

Fig. 10.13 Program participation for women, 2009

Sources: Current Population Survey and Social Security Administration.

smaller role than in 1970, reflecting the cohort pattern of military participation. The SSDI participation rates are double what was seen in 1970. Unemployment Insurance now decreases across age groups, possibly reflecting the kind of substitution found in Autor and Duggan (2003). For the women in figure 10.13, SSDI rates are much higher than in 1970 because not only are more working women claiming SSDI, but there are many more working women. Unemployment Insurance receipt declines after age fifty-four, but other benefits show little participation.

I now isolate just recipiency of SSDI. In figure 10.14 I graph the SSDI recipiency rate for three different age groups for men. The broad trends of receipt are the same across the three age groups, although at different levels. There is a peak at 1980, reflecting the tightening of medical screening starting in the late 1970s and the legislated changes in 1980. The loosening of rules in 1984 doesn't appear to have an immediate impact here, with SSDI rates for sixty to sixty-four-year-olds not reaching their 1980 height again until the second half of the 2000s. Growth in the rolls at younger ages is evident, though, as the 1980 peak is surpassed in the early 1990s at ages forty to forty-four and fifty to fifty-four. This suggests that much of the growth for males in the 1980s and 1990s came from younger ages.

The women are graphed in figure 10.15. The rate of SSDI recipiency peaks at 1980, just like for the men. However, the growth rate takes off after 1990 - especially for those aged sixty to sixty-four. By 2009, recipiency rates at all ages for women were more than double what was seen in 1980 .

The analysis of program participation has revealed several interesting findings. First, SSDI has moved from one program among many, to being 


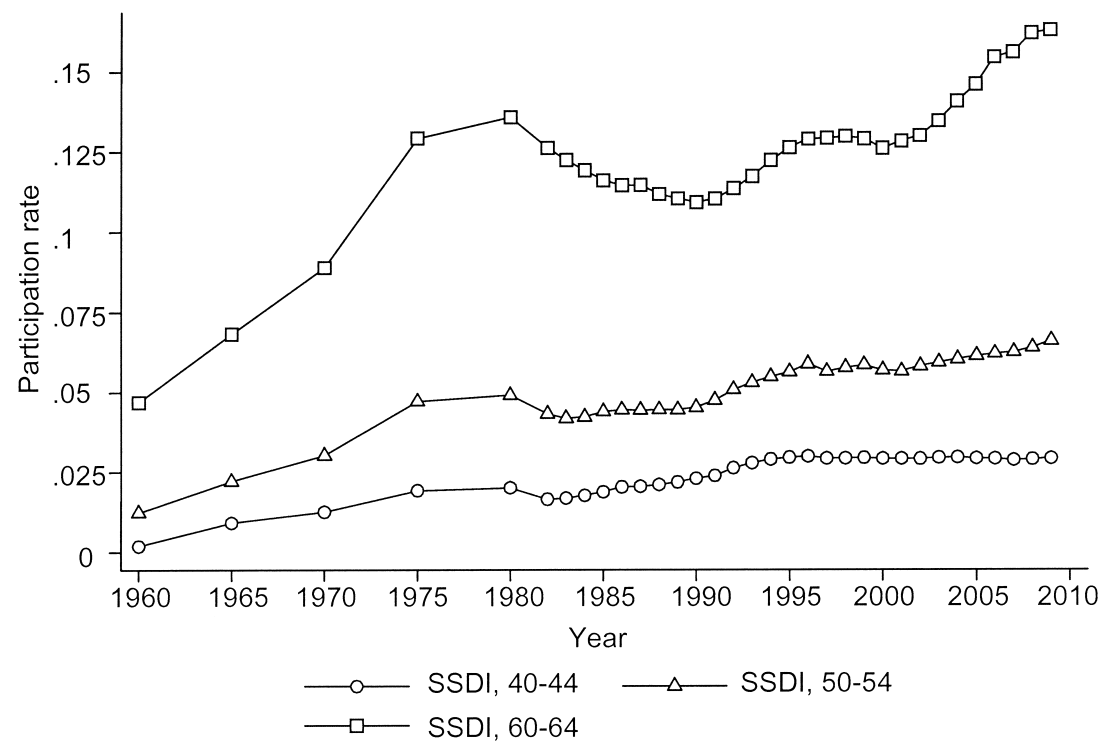

Fig. 10.14 SSDI receipt for men

Sources: Social Security Administration and US Census Bureau population estimates.

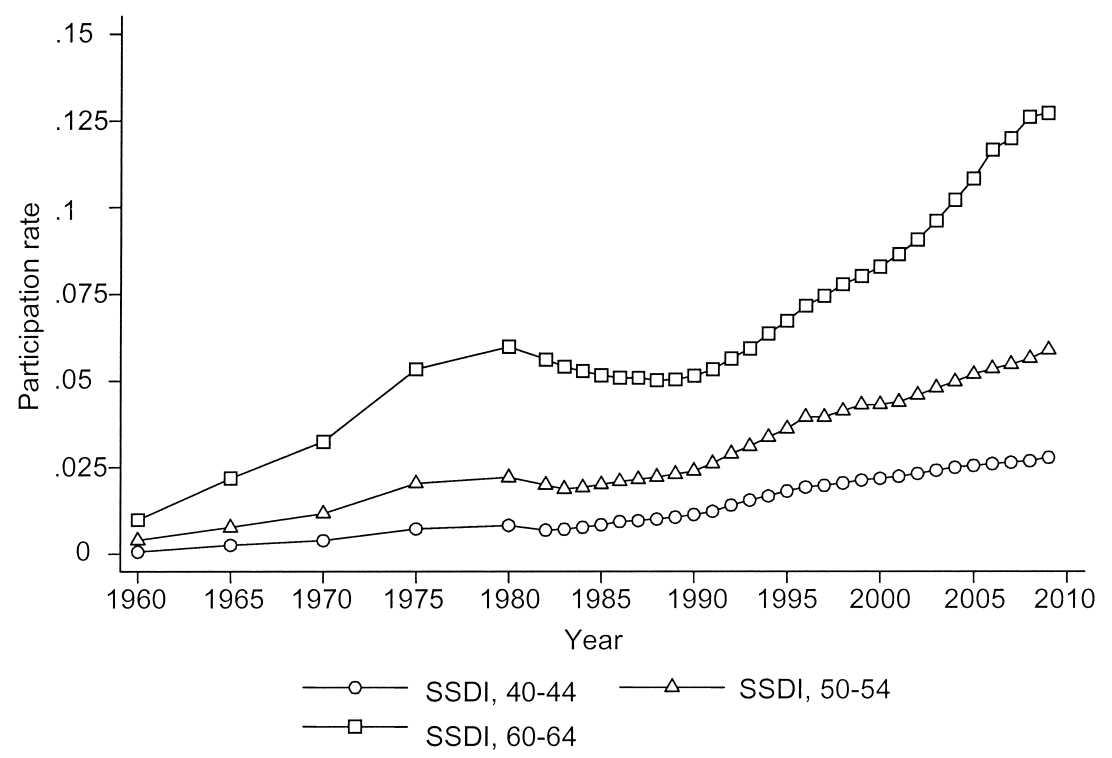

Fig. 10.15 SSDI receipt for women

Sources: Social Security Administration and US Census Bureau population estimates. 
the dominant program supporting nonworking older people in the United States. The growth in SSDI receipt has been accompanied by dips in Veterans' Benefits and a possible offset with Unemployment Insurance receipt at ages sixty to sixty-four. The largest growth is found for women and for men at middle ages.

\subsubsection{Labor Markets and Disability}

It is clear from the preceding analysis that labor market trends are very important for understanding what is going on with SSDI receipt. For example, the exceptional growth of receipt for women likely reflects the increasing workforce attachment of the cohorts of women arriving at older ages in the 1980s, 1990s, and 2000s. In this set of results, I graph employment, unemployment, and labor force nonattachment by sex and age groups. I also decompose the reason not working into retirement and disability components. All of this analysis is performed with the CPS.

The employment rates for the age groups forty to forty-four, fifty to fiftyfour, and sixty to sixty-four are shown in figure 10.16 for men. The first two age groups show a very slight downward trend, but the level of employment remains very high. Business cycle effects do not appear terribly large at these ages for men. For ages sixty to sixty-four, there is a steady drop in the employment rate from the 1960s to the mid-1990s. The total drop is 39 percent from the 1962 starting point for age sixty to sixty-four men. After 1995 , the employment rate for men in this age group recovers slightly. Schirle

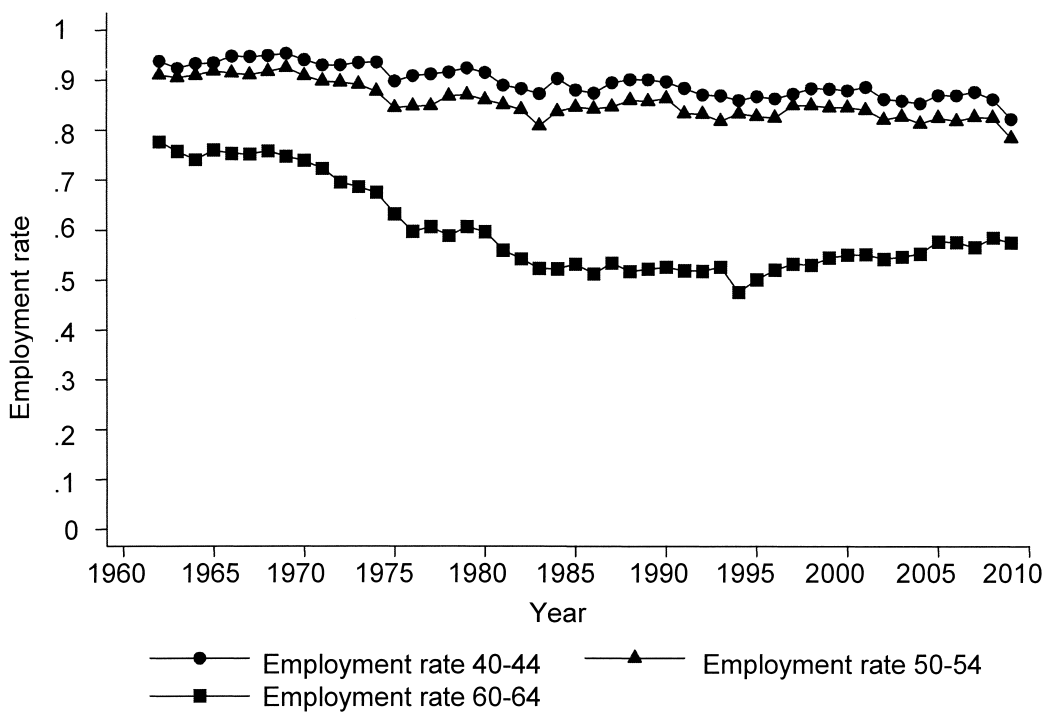

Fig. 10.16 Employment rates by age for men

Source: Current Population Survey. 


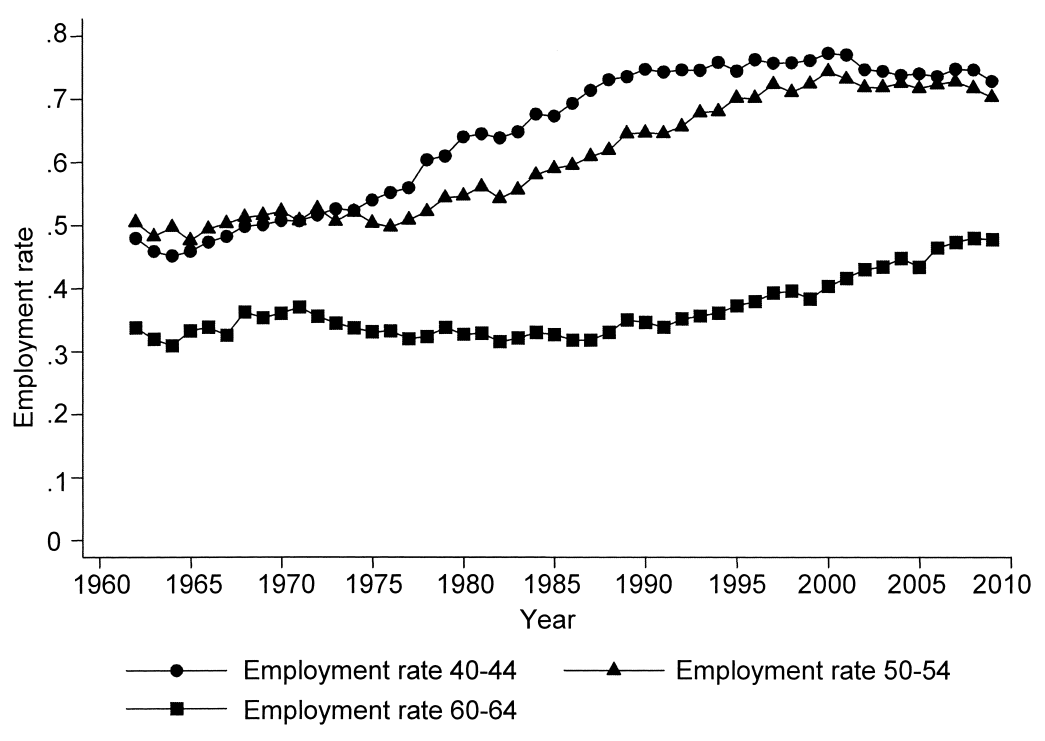

Fig. 10.17 Employment rates by age for women

Source: Current Population Survey.

(2008) presents evidence that this in part reflects the possibility of joint retirement for men in this cohort, who are married to women from cohorts with much stronger lifetime workforce attachment.

These increasing female cohort employment patterns can be seen in figure 10.17, which shows the employment rates for women for the same three age groups. The breakout in employment at age forty to forty-four in the 1970s and 1980s leads to higher employment in the 1980s and 1990s for ages fifty to fifty-four, and then the 1990s and 2000s for ages sixty to sixty-four. This higher rate of employment not only helps to explain the pattern of male employment at ages sixty to sixty-four, but also has very important implications for SSDI. The rate of sixty to sixty-four-year-old female employment is 36.7 percent higher in 2009 than it was in 1989. This suggests that many more women are likely eligible to claim SSDI than was the case in the 1970s and 1980s. Indeed, Duggan and Imberman (2009) find that increasing eligibility can explain around one quarter of total SSDI growth for women.

Figures 10.18 and 10.19 examine unemployment rates at different ages. Here, business cycle effects can be seen clearly, with peaks in the early 1980s, 1990s, 2000s, and in 2009. The level of unemployment for women is lower, but the age dispersion of unemployment rates appears larger than for men. This may stem from the large cohort differences in labor market attachment for women.

There are strong sex differences for being out of the labor force. The rate of nonparticipation in the labor market is graphed in figure 10.20 for men 


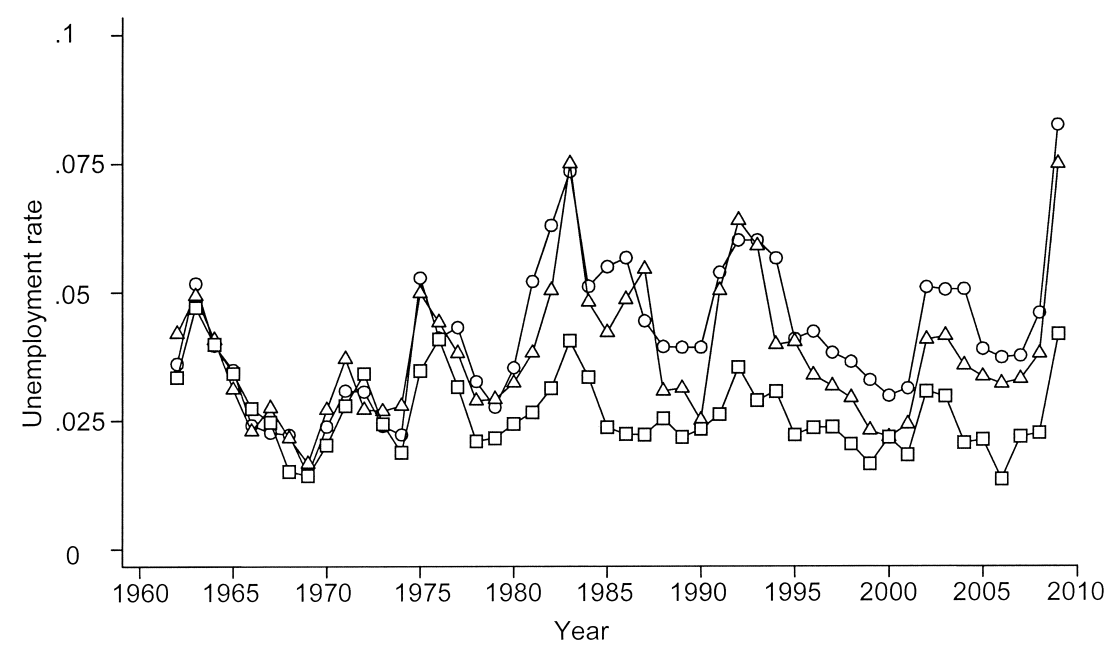

$\_$Unemployment rate 40-44 $\triangle \triangle$ Unemployment rate 50-54

$\square-$ Unemployment rate 60-64

Fig. 10.18 Unemployment rates by age for men

Source: Current Population Survey.

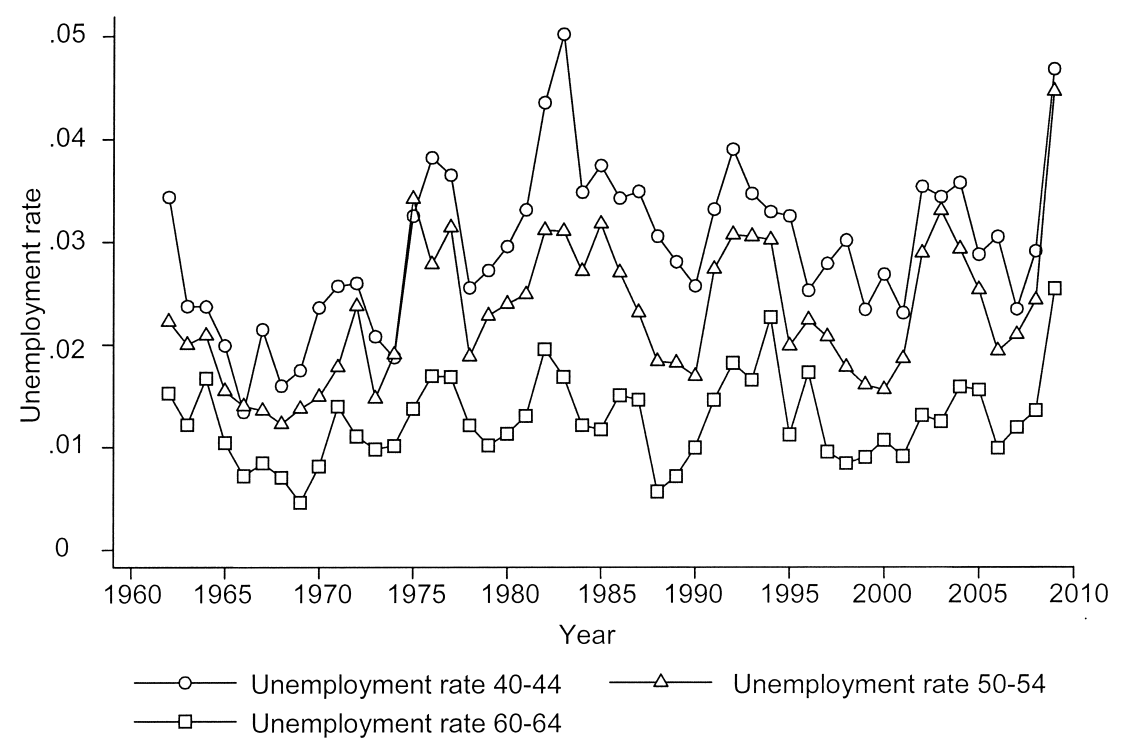

Fig. 10.19 Unemployment rates by age for women

Source: Current Population Survey. 


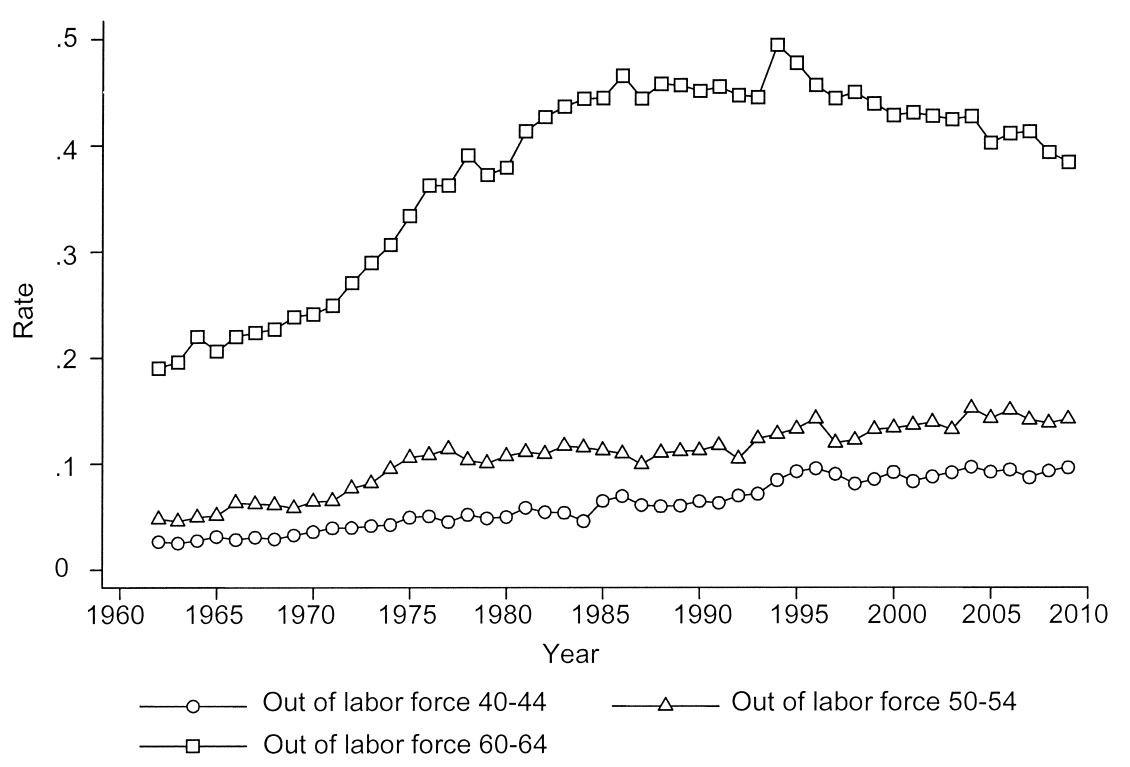

Fig. 10.20 Not in the labor force by age for men

Source: Current Population Survey.

and figure 10.21 for women. In both cases, however, these trends provide near mirror image graphs for the trends discussed previously for employment.

More informative, however, are the reasons why men and women are not working. The CPS asks those who haven't worked at all in the past year the main reason why that person did not work. Two of the coded responses are "ill or disabled" and "retired." 15 Figure 10.22 graphs these data for men from 1968 to 2009. For men, the proportion of men not working at ages sixty to sixty-four more than doubles from the late 1960s to the mid-1990s. Most of this growth, however, comes from retirement. The proportion of men not working because of illness or disability is relatively constant. In fact, from the late 1970s onward, it declines slightly. There is no sign of the increase seen in SSDI recipiency starting in the late 1980s and continuing on forward. Here, not working because of disability is flat through time.

The responses of women are graphed in figure 10.23. The nature of the graph is very different for women because the category "taking care of home or family" is the most important until the 1990s for these age sixty to sixtyfour-year-old women. By the 2000s, like men, most women not working are doing so because either of retirement or disability. Most curious is the relatively constant rate of not working because of disability. In figure 10.15,

15. The other valid responses in 2009 are "taking care of home or family," "going to school," and "could not find work." There have been slight changes to the question since. 


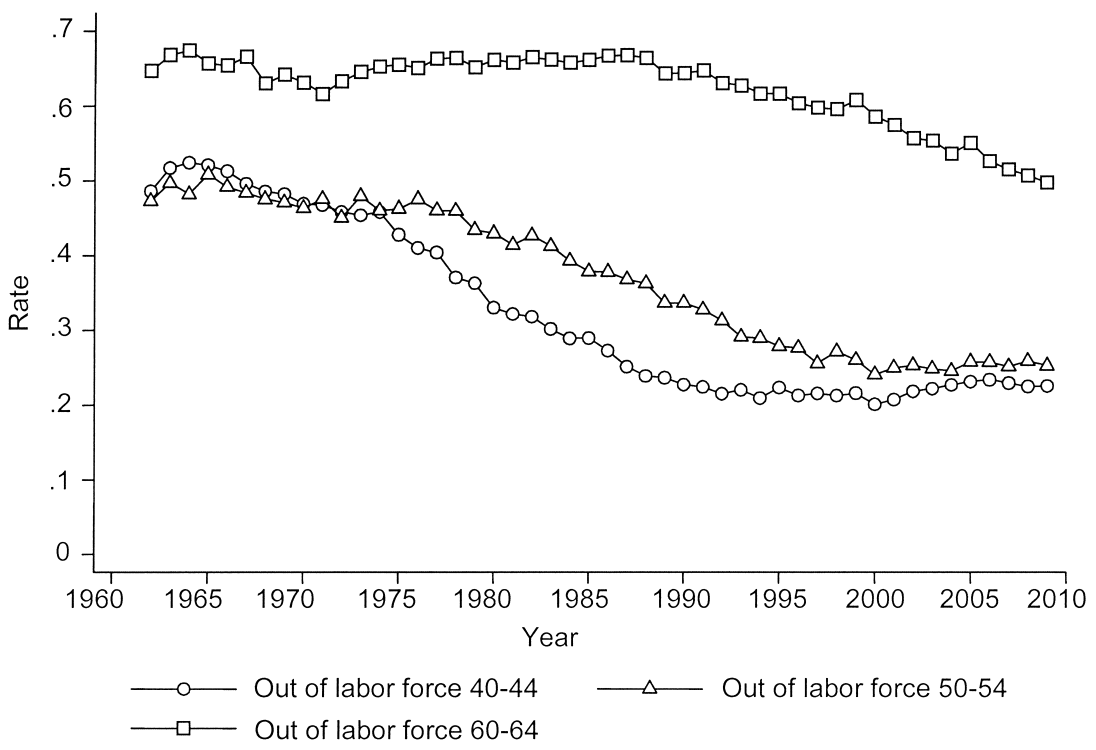

Fig. 10.21 Not in the labor force by age for women

Source: Current Population Survey.

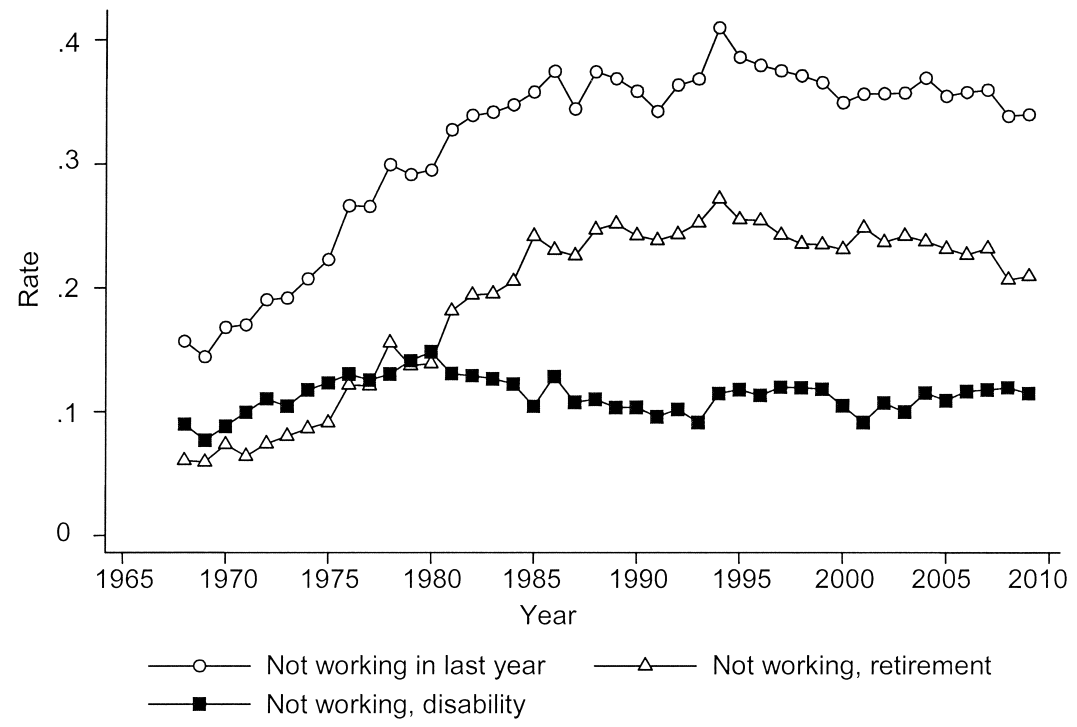

Fig. 10.22 Reasons not working, aged sixty to sixty-four men Source: Current Population Survey. 


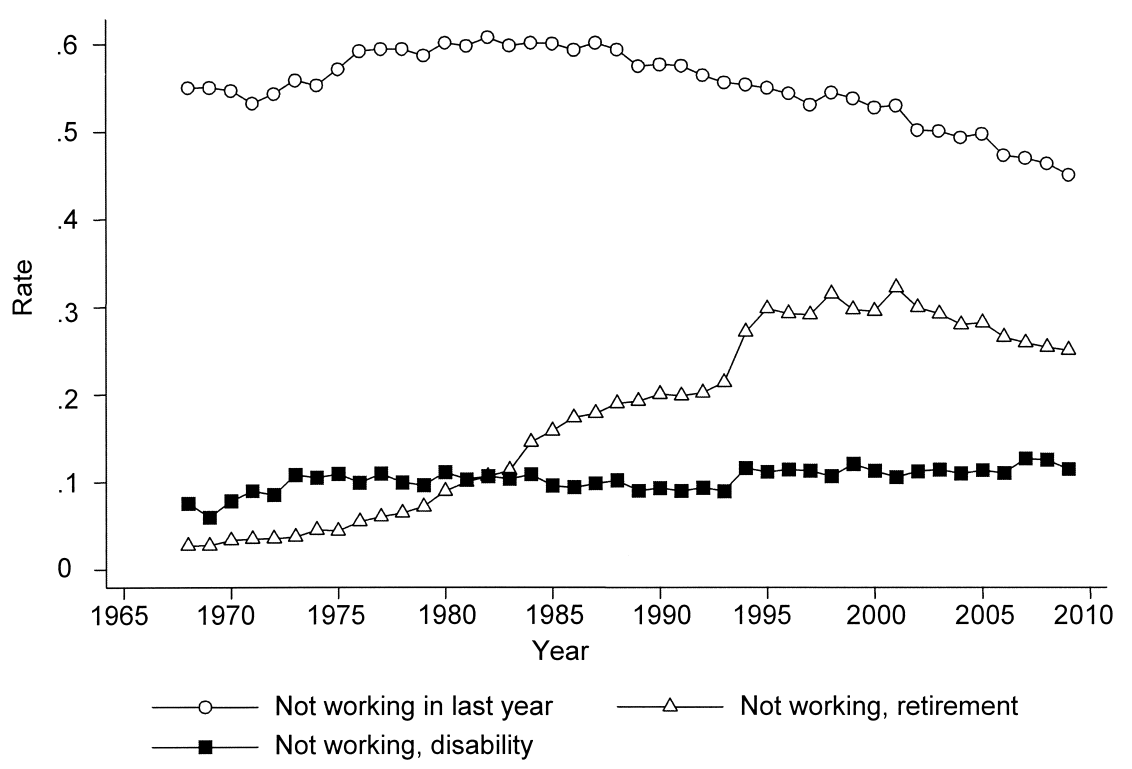

Fig. 10.23 Reasons not working, aged sixty to sixty-four women Source: Current Population Survey.

SSDI recipiency for women more than doubled from 1985 to 2009. Here, there is no sign of an increase.

For another view on employment rates, I look in figure 10.24 at the relationship between employment and mortality. Each point on the graph is a plot of employment versus mortality for a given age. I use ages fifty to seventy-five. Taking the years 1996 and 2006, I compare how much employment is observed at different levels of mortality. In 1966, it took a mortality rate of 0.04 to reduce employment to around 50 percent of males. In 2006, the same 50 percent employment rate was reached at a much lower mortality rate-around 0.018 . This suggests that, for the same level of health (as measured by mortality), there was much more work in 1966 than in 2006.

Figure 10.25 repeats this analysis for women. The graph here is more difficult to interpret because of the great increase in employment rates among females over the decades. Still, there are signs of a small change in employment for a given level of mortality in the middle of the chart.

The analysis of employment behavior uncovers two important findings. First, the emergence of widescale female labor force participation is a dominant factor in understanding the trends in SSDI over this past thirty years. Second, despite large increases in SSDI recipiency, the proportion of both men and women reporting that their absence from the labor market is caused by illness or disability is relatively constant. This could suggest that the upswing in SSDI recipiency is due to SSDI taking an increasing share of 


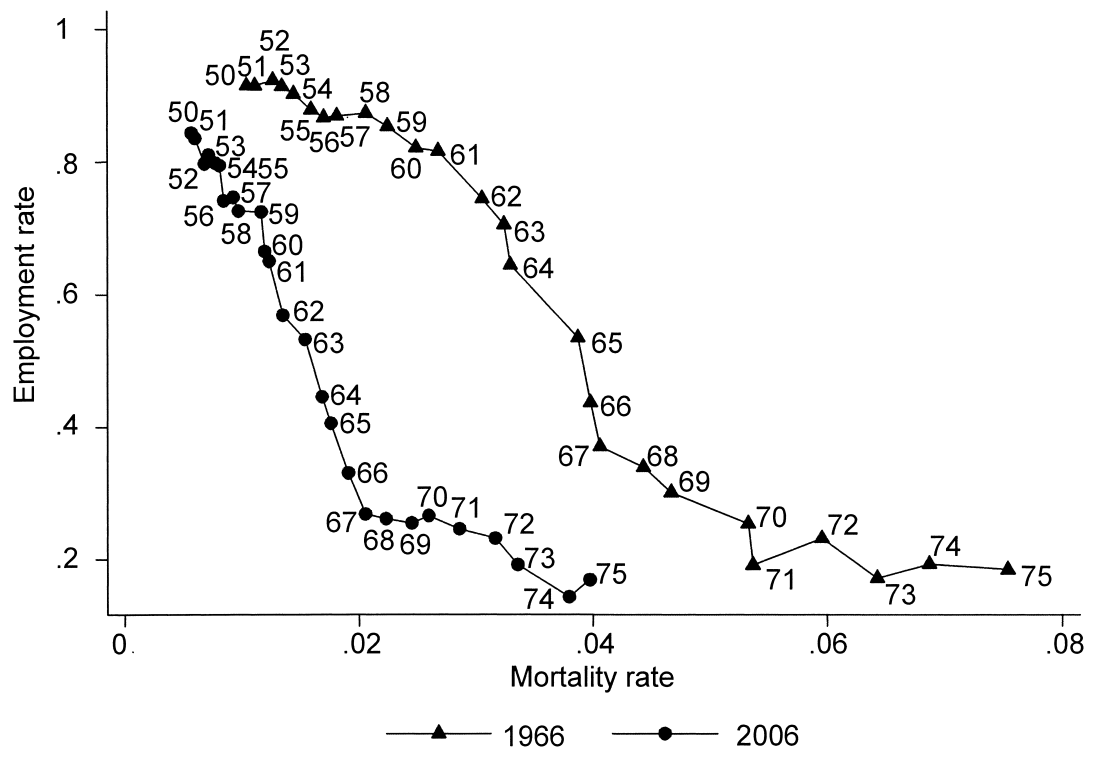

Fig. 10.24 Employment and mortality, men

Sources: Current Population Survey for employment and mortality data from National Center for Health Statistics and US Census Bureau.

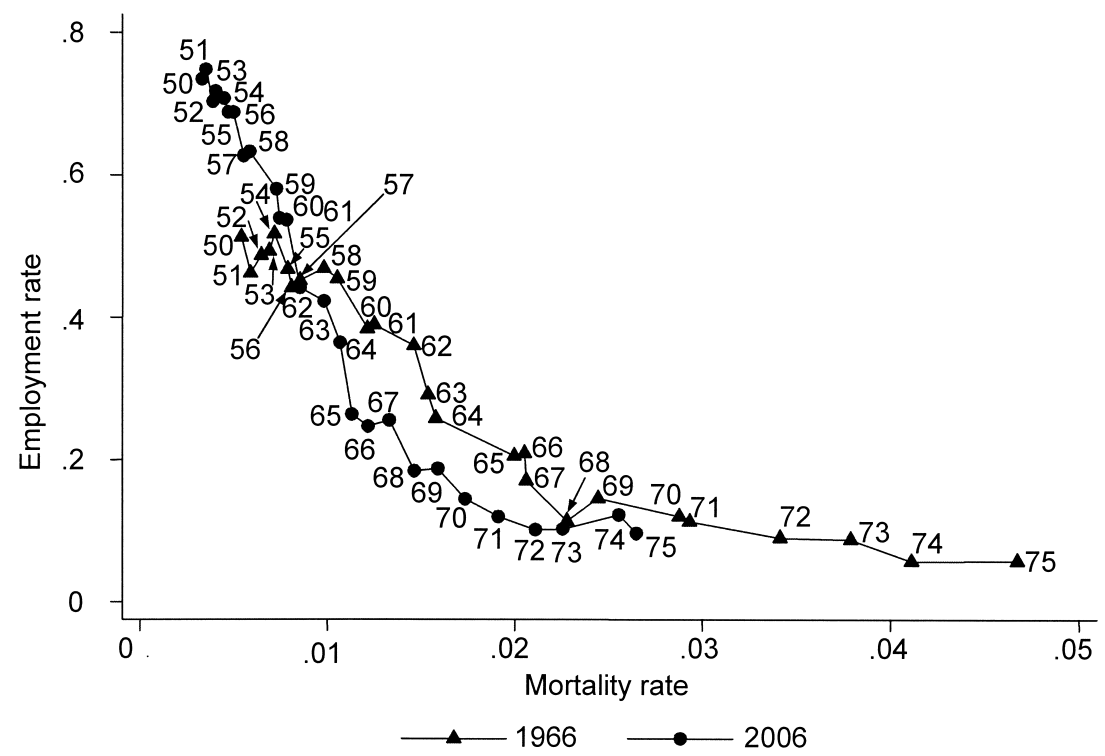

Fig. 10.25 Employment and mortality, women

Sources: Current Population Survey for employment and mortality data from National Center for Health Statistics and US Census Bureau. 
those who were not working because of disability, but who previously had no resort to SSDI because of the type of illness or other eligibility factors.

\subsubsection{Disability and Health}

The final set of results looks more deeply at the relationship between SSDI, other measures of disability, and health. This continues the investigation of the finding immediately in the preceding that the proportion out of the labor force for disability does not seem to line up well with trends in SSDI uptake. In the following, I graph two measures of disability against mortality rates and self-assessed health measures. The goal here is to ascertain what relationship measured disability has with measures of health.

Figure 10.26 looks at mortality, not working because of a disability, and SSDI receipt for men aged forty-five to forty-nine. All of these variables have been used previously in this chapter, but putting them together in one place brings new insight. Specifically, the strong improvements in mortality over the period from 1972 to 2009 move in a starkly opposite direction to the two disability measures. To the extent that mortality captures important aspects of health, this suggests that heath has been getting better, while disability measures show increasing disability. For the two disability measures, they both trend up sharply over this time period. Social Security Disability

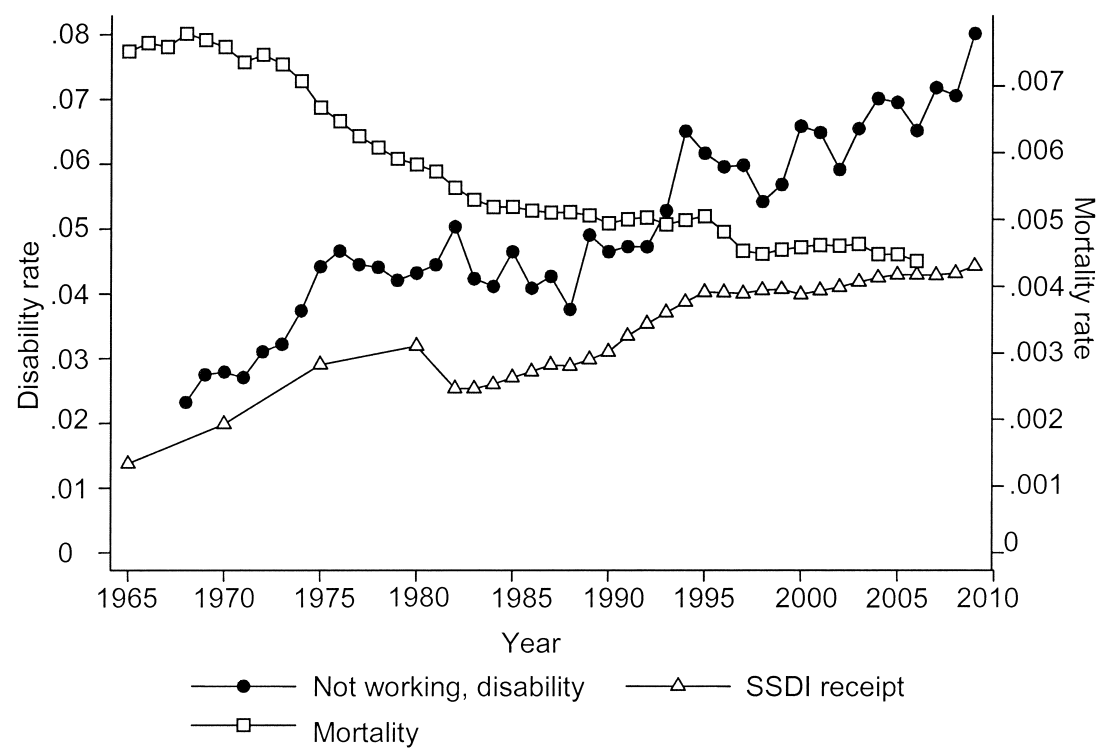

Fig. 10.26 Disability, SSDI receipt, and mortality for aged forty-five to forty-nine men

Sources: Not working because of a disability is from the Current Population Survey. SSDI receipt is from the Social Security Administration and US Census Bureau. Mortality data from National Center for Health Statistics and US Census Bureau. 
Insurance receipt is below the proportion this is not working because of a disability. This may be because of eligibility issues - not everyone who can't work is able to draw on SSDI if, for example, they haven't worked sufficiently to gain the number of credits needed for SSDI benefits. The other possibility is that they are simply measuring different things.

For women aged forty-five to forty-nine, figure 10.27 shows a very similar pattern. The largest difference between women and men is the magnitude of the gap between those not working because of a disability and SSDI receipt. This larger gap is likely rooted in the larger proportion of women who have not earned sufficient credits to qualify for SSDI. Of course, the overall rates here are quite low as most forty-five to forty-nine-year-olds are relatively healthy.

I now repeat the analysis, using men aged sixty to sixty-four. Figure 10.28 reveals the same steady downward trend in mortality seen at younger ages. For disability, SSDI receipt and not working because of a disability are quite close to each other until 2000. This might mean that most men of this age are eligible so that SSDI captures almost all of the men who are disabled. There is a divergence after 2000, with SSDI receipt taking off higher than being out of work with a disability. This is hard to reconcile with eligibility because more seem to be receiving SSDI than are reporting not working because of a disability.

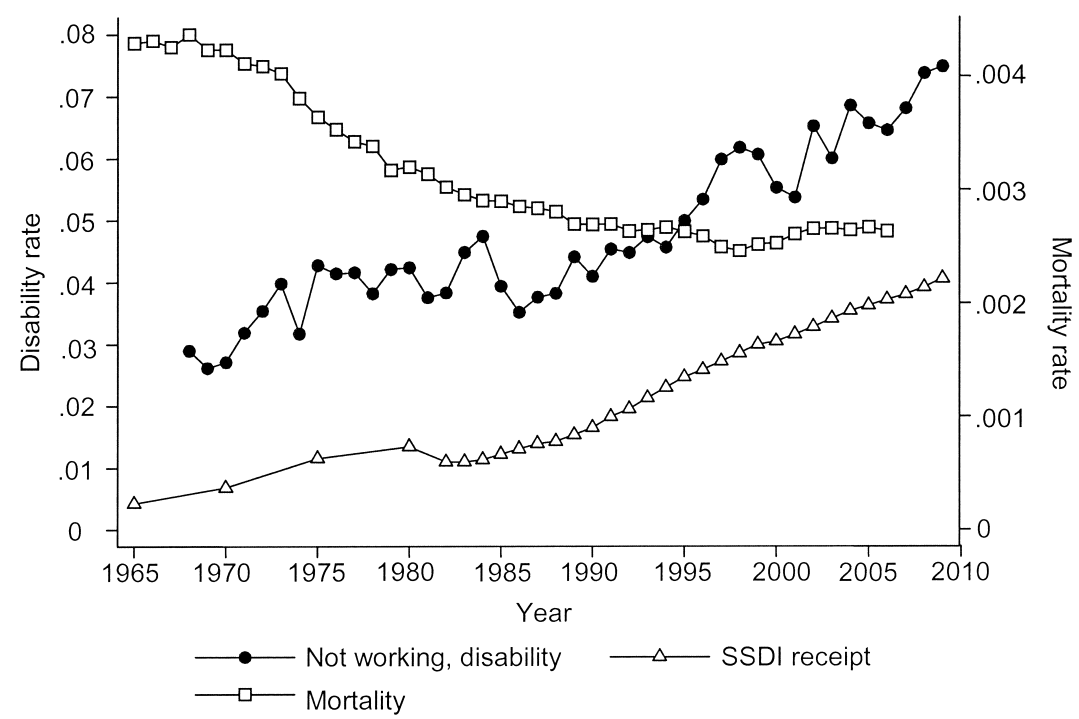

Fig. 10.27 Disability, SSDI receipt, and mortality for aged forty-five to forty-nine women

Sources: Not working because of a disability is from the Current Population Survey. SSDI receipt is from the Social Security Administration and US Census Bureau. Mortality data from National Center for Health Statistics and US Census Bureau. 


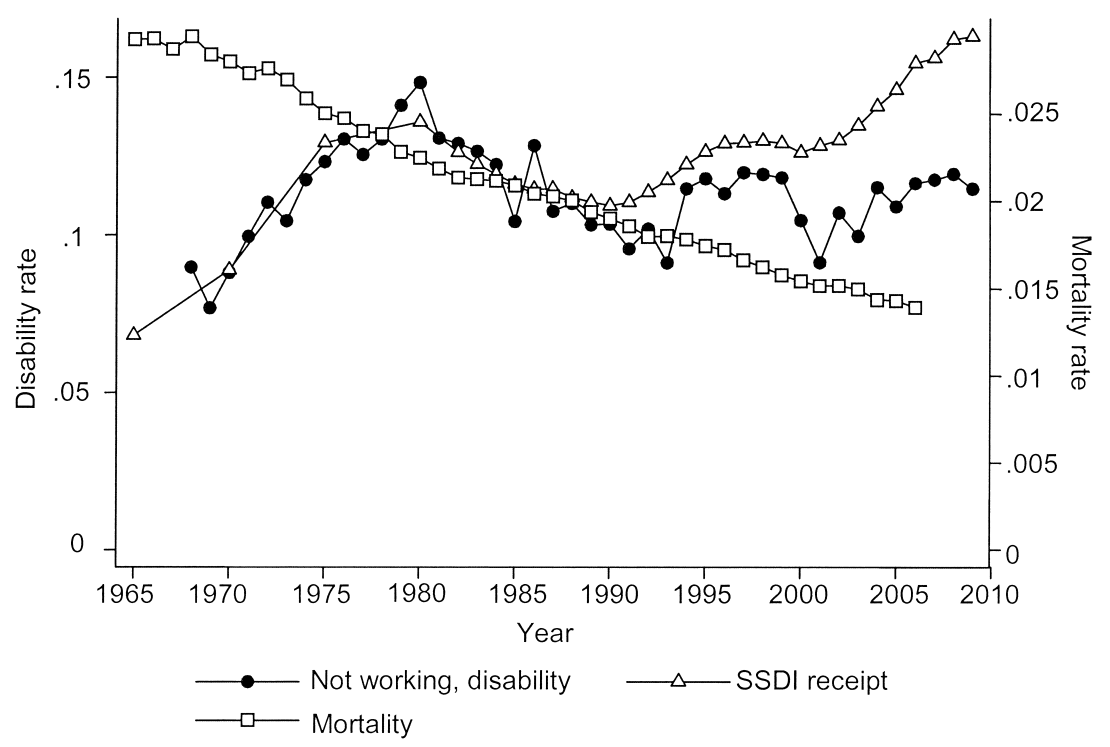

Fig. 10.28 Disability, SSDI receipt, and mortality for aged sixty to sixty-four men Sources: Not working because of a disability is from the Current Population Survey. SSDI receipt is from the Social Security Administration and US Census Bureau. Mortality data from National Center for Health Statistics and US Census Bureau.

For women aged sixty to sixty-four, the gap between the measures of disability in figure 10.29 closes over the fifteen years from 1990 to 2005. Again, this may reflect increased eligibility or different underlying phenomena for the two measures. However, neither measure of disability shows any relationship with the mortality rate.

As discussed earlier, the mortality rate is an abrupt measure of health. With this in mind, I repeat the preceding analysis but include the selfassessed fair or poor health measure taken from the GSS, as used earlier.

Figures 10.30 and 10.31 show men and women at ages forty-five to fortynine. In both cases, there is a gentle improvement in health as measured by those suffering from fair or poor health over this time period. Both measures of disability move up, which is at odds with the self-assessed health trend.

The final two figures have men and women ages sixty to sixty-four and compare fair or poor health to measures of disability. Figure 10.32 shows a slight downward trend for fair or poor health for men, but figure 10.33 has a clear downward trend for the health of women in this age range. The disability measures show no obvious correspondence with the health measure.

This section of results investigated the relationship between health and disability measures. The data revealed starkly opposite trends both for mortality and self-assessed health when compared to disability. For the two disability measures, the proportion reporting not working because of dis- 


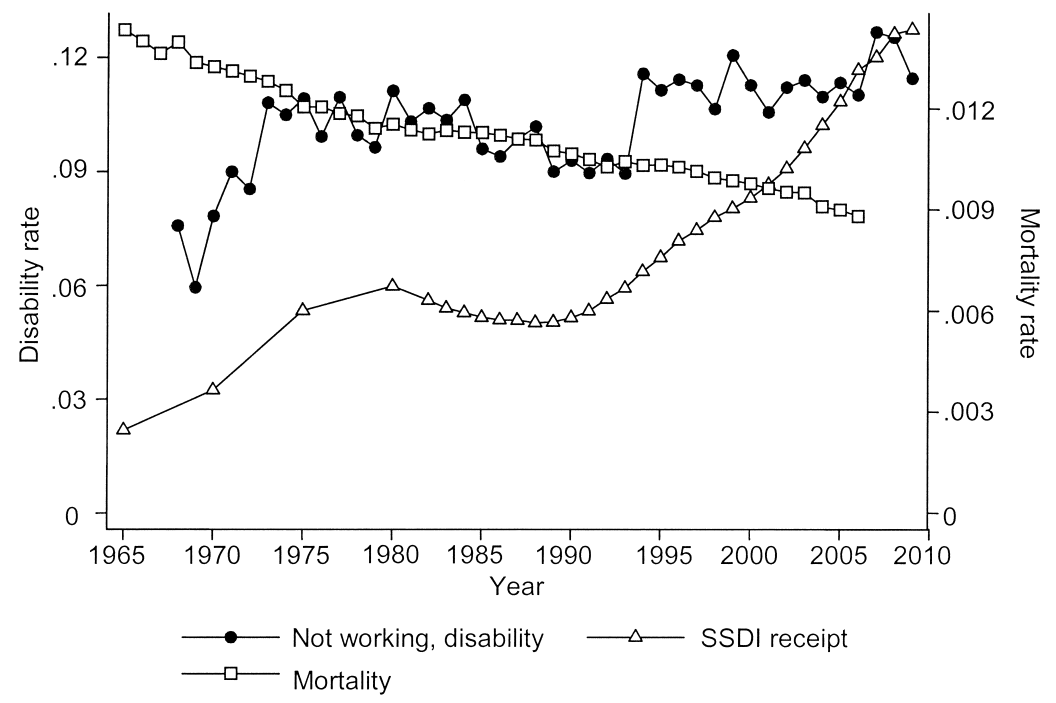

Fig. 10.29 Disability, SSDI receipt, and mortality for aged sixty to sixty-four women

Sources: Not working because of a disability is from the Current Population Survey. SSDI receipt is from the Social Security Administration and US Census Bureau. Mortality data from National Center for Health Statistics and US Census Bureau.

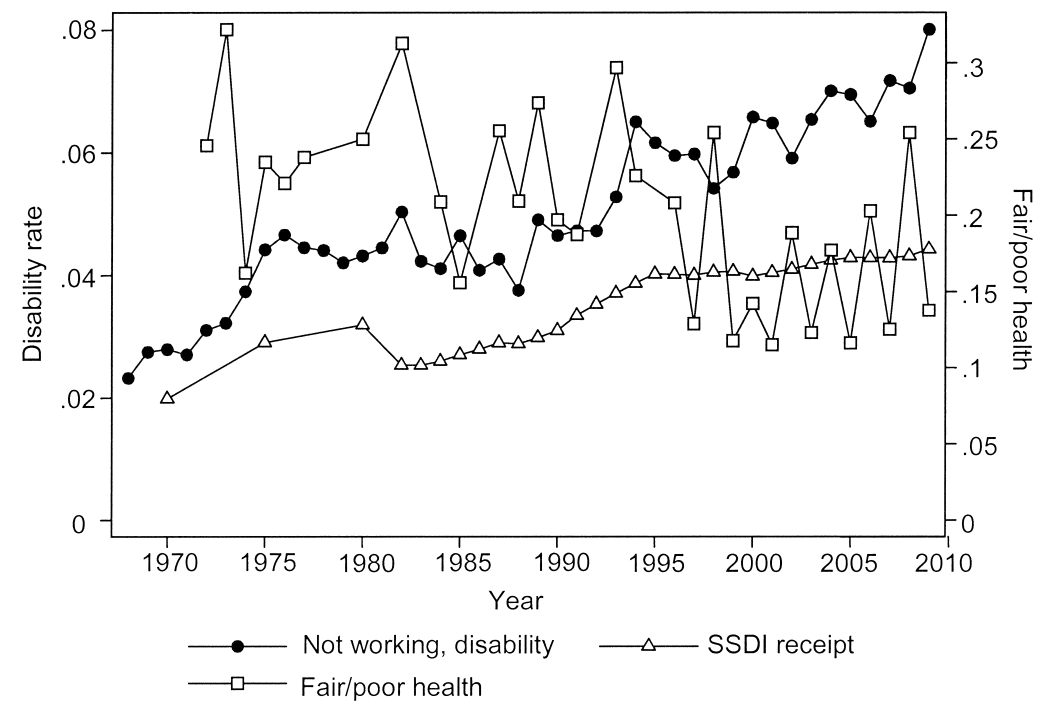

Fig. 10.30 Disability, SSDI receipt, and fair or poor health for aged forty-five to forty-nine men

Sources: Not working because of a disability is from the Current Population Survey. SSDI receipt is from the Social Security Administration and US Census Bureau. Health data from General Social Survey. 


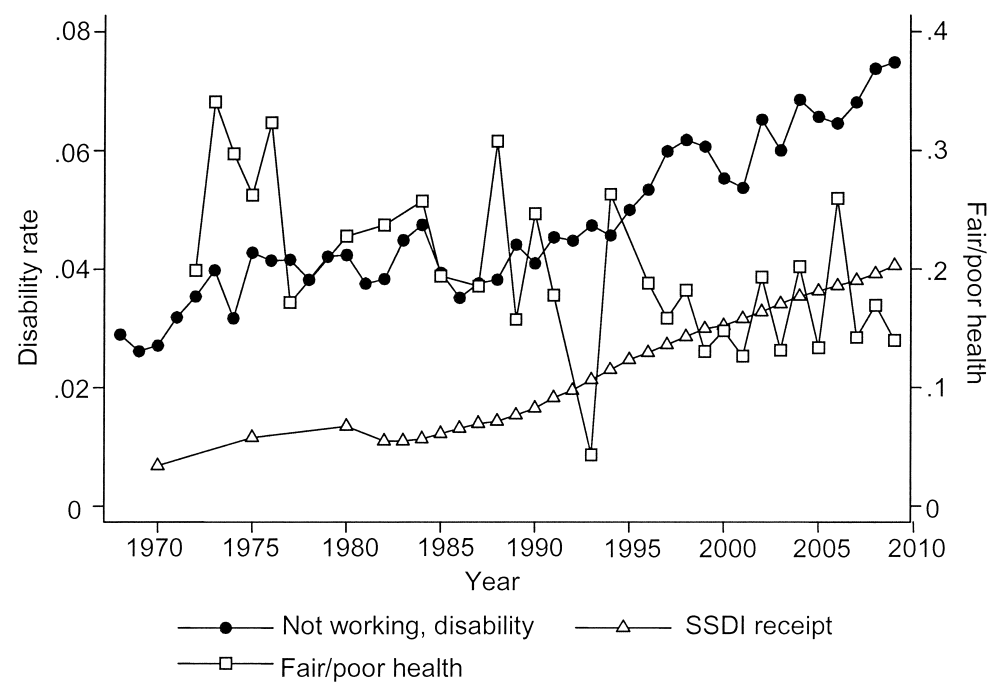

Fig. 10.31 Disability, SSDI receipt, and fair or poor health for aged forty-five to forty-nine women

Sources: Not working because of a disability is from the Current Population Survey. SSDI receipt is from the Social Security Administration and US Census Bureau. Health data from General Social Survey.

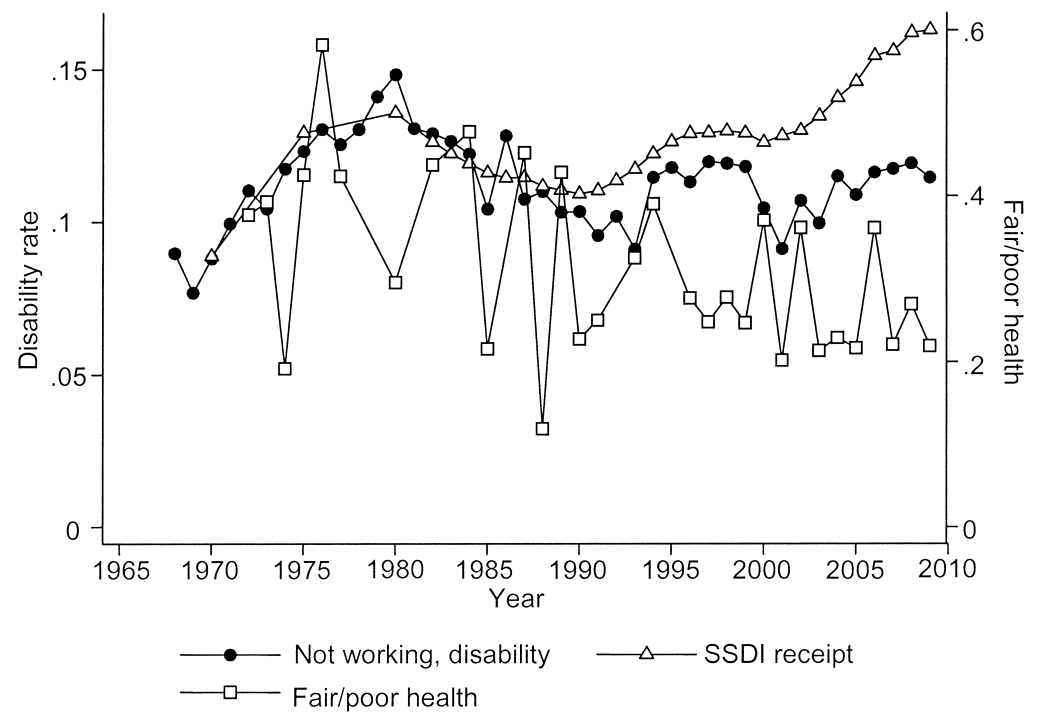

Fig. 10.32 Disability, SSDI receipt, and fair or poor health for aged sixty to sixty-four men

Sources: Not working because of a disability is from the Current Population Survey. SSDI receipt is from the Social Security Administration and US Census Bureau. Health data from General Social Survey. 


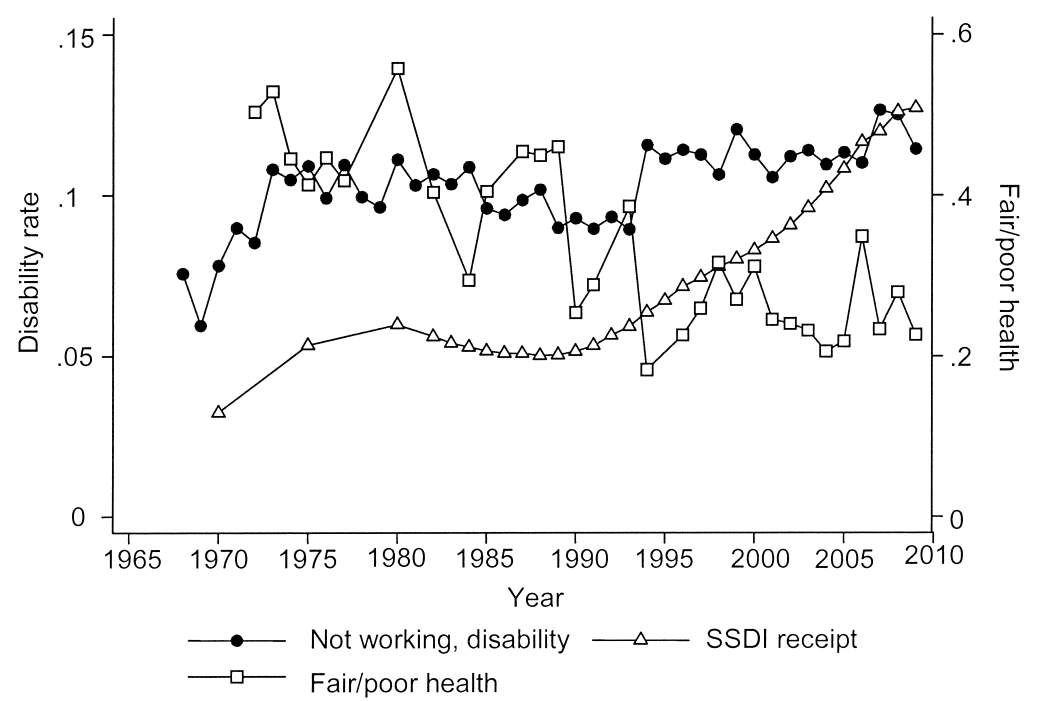

Fig. 10.33 Disability, SSDI receipt, and fair or poor health for aged sixty to sixty-four women

Sources: Not working because of a disability is from the Current Population Survey. SSDI receipt is from the Social Security Administration and US Census Bureau. Health data from General Social Survey.

ability was often higher than the proportion receiving SSDI benefits. This gap may indicate the extent of ineligibility among the disabled, or it may indicate that movements in SSDI benefit recipiency are not strongly related to work-limiting disability.

\subsection{Conclusion}

This chapter has examined the long-run trends in health, employment, and disability among older Americans. By taking a very long time horizon for the analysis, several interesting findings emerge. First and foremost, the long-run trends in takeup of SSDI seem to bear little obvious relationship to trends in health, as measured by mortality and subject self-assessed health. Instead, the movements in SSDI recipiency seem most related to changes in the legislative and administrative framework as well as the increasing employment (and, thus, potential eligibility) of women.

Also, the correspondence of SSDI recipiency with being out of the labor market because of illness or disability wasn't as strong as one might expectat ages sixty to sixty-four, SSDI recipiency has increased substantially without a similar increase in the proportion not working because of disability. This may be due to changes in eligibility, meaning that SSDI captures an increasing fraction of those not working because of disability. On the other 
hand, it may indicate that the increases in SSDI are not driven by those not working because of a disability.

Autor and Duggan (2006) and Duggan and Imberman (2009) have forecasted serious trouble for the SSDI program on the horizon. The longrun analysis in this chapter, along with the experience of other countries reported in other parts of this project, should provide some perspective as Americans grapple with the challenges with SSDI.

\section{References}

Autor, David H., and Mark G. Duggan. 2003. "The Rise in the Disability Rolls and the Decline in Unemployment." Quarterly Journal of Economics 118 (1): 157-205. .2006. "The Growth in the Social Security Disability Rolls: A Fiscal Crisis Unfolding." Journal of Economic Perspectives 20 (3): 71-96.

Berkowitz, Edward D. 1989. Disabled Policy: America's Programs for the Handicapped. Cambridge: Cambridge University Press.

-2000. "Statement before the Subcommittee on Social Security of the Committee on Ways and Means." June 13. https://socialsecurity.gov/history/edberkdib .html.

Bound, John. 1989. "The Health and Earnings of Rejected Disability Insurance Applicants." American Economic Review 79 (3): 482-503.

Duggan, Mark, and Scott A. Imberman. 2009. "Why Are the Disability Rolls Skyrocketing? The Contribution of Population Characteristics, Economic Conditions, and Program Generosity." In Health at Older Ages: The Causes and Consequences of Declining Disability, edited by David M. Cutler and David A. Wise, 337-79. Chicago: University of Chicago Press.

Gruber, Jonathan, and Jeffery D. Kubik. 1997. "Disability Insurance Rejection Rates and the Labor Supply of Older Workers." Journal of Public Economics 64 (1): $1-23$.

Parsons, Donald O. 1980. “The Decline of Male Labor Force Participation.” Journal of Political Economy 88 (1): 117-34.

Schirle, Tammy. 2008. "Why Have the Labor Force Participation Rates of Older Men Increased Since the mid-1990s?” Journal of Labor Economics 26 (4): 549-94.

Social Security Administration. 1986. "A History of the Social Security Disability Programs." http://segurosocial.gov/history/1986dibhistory.html.

. Various years. Annual Statistical Supplement to the Social Security Bulletin. Woodlawn, MD: US Social Security Administration. 